\title{
Mikro Ölçekli Girişimlerde Pazar Yönlülüğün Yenilik Performansı Üzerindeki Etkisi: Eskişehir'deki Mikro Ölçekli Girişimlerde Bir Araştırma $^{1}$
}

\author{
Effect of Market Orientation on Innovation Performance of Micro \\ Enterprises: Research on Micro Enterprises in Eskişehir
}

\author{
Nurcan TURAN \\ Anadolu Üniversitesi \\ İktisadi ve İdari Bilimler Fakültesi, \\ İşletme Bölümü, \\ Eskişehir, Türkiye \\ nturan@anadolu.edu.tr
}

\author{
İçlem ER \\ Dumlupınar Üniversitesi \\ İktisadi ve İdari Bilimler Fakültesi, \\ Uluslararası Ticaret ve Finansman \\ Bölümü, Kütahya, Türkiye \\ iclem.er@dpu.edu.tr
}

\section{Özet}

Pazar yönlülük ve yenilik performansı arasındaki ilişkiyi ele alan çalışmalar, genellikle büyük işletmeler düzeyinde gerçekleştirilmiştir. Bu araştırmada, Eskişehir' de faaliyet gösteren mikro ölçekli girişimlerin yenilik performansı üzerinde pazar yönlülüğün etkisi incelenmiştir. Pazar yönlülügün yanı sıra, mikro girişimlerin yaşadığ işletmecilik sorunlarının da yenilik performansı üzerinde bir etkisi olup olmadığı tespit edilmeye çalışılmıştır. Farklı sektörlerden 1769 mikro girişimden toplanan verilerden elde edilen bulgulara göre, pazar yönlülüğün rakip odaklılık ve işletme içi koordinasyon boyutu ile mikro işletmelerin yaşadığı genel işletmecilik sorunlarının yenilik performansı üzerinde etkili olduğu tespit edilmiştir. Araştırma pazar yönlülük yaklaşımının mikro girişimlerde de geçerli olduğunu, ancak değişen işletme koşullarına bağlı olarak, mikro girişimler düzeyinde yeni bir pazar yönlülük uyarlamasının yapılması gerekliliğini ortaya koymuştur.

Anahtar Kelimeler: Mikro girişimler, pazar yönlülük, yenilik performansı, mikro girişimlerin işletmecilik sorunları, işbirliği ve ortaklık kültürü.

\section{Abstract}

Most research on market orientation and its effect on innovation performance are related to large firms. This study aims to investigate the effect of market orientation on innovation performance of micro enterprises operating in Eskisehir. In addition to market orientation, this research also tries to explore whether business problems that micro enterprises encounter would have an impact on innovation performances of these enterprises. To test the proposed relationships, data gathered from 1769 micro

\footnotetext{
${ }^{1}$ Bu araştırma, Anadolu Üniversitesi Bilimsel Araştırma Projeleri tarafından desteklenmiştir, Proje No: 1002E92.
} 
enterprises operating in various areas was used, and the analysis revealed that market orientation and business problems micro enterprises encounter have significant impact on innovation performance. The research confirmed that market orientation behavior applies to micro enterprises, however, it also demonstrated that a new approach of market orientation is essential for micro enterprises due to changing business circumstances.

Keywords: Micro enterprises, market orientation, innovation performance, business problems of micro enterprises, collaboration and cooperation culture.

\section{Giriş}

Günümüzde sürekli artan rekabet ve değişen pazar koşulları, işletmelerin varlıklarını sürdürme çabalarını artırmalarına yol açmaktadır. Bu durumda işletmeler rekabet güçlerini artırabilmek için pazar yönlü, değişime ve yeniliğe açık olma yönünde çaba harcamaktadır. Özellikle hızla değişen teknoloji, işletmeleri yeni ürünler geliştirme ve yeni yöntem ve stratejiler izleme konusunda zorlamaktadır.

Günümüzün başarılı işletmelerinin temel amaçlarının başında, müşteri memnuniyeti gelmektedir. $\mathrm{Bu}$ nedenle, işletmelerin odak noktasında müşteri yer almaktadır. İşletmeler için, yalnızca ürünlerini satın alacak müşterileri bulmak değil, aynı zamanda bu müşterileri elde tutabilmek de önemlidir. Bunun için, işletmeler hızla değişen müşteri taleplerine uyum sağlayabilme açısından yenilikçi politikalar izlemek zorundadır. Peter Drucker'a (1973) göre, “işletmelerin yegâne amacı müşteri yaratmaktır; bu nedenle işletmelerin yalnızca iki fonksiyonu vardır: Pazarlama ve yenilik yapma". Rekabet gücünün artırılmasında önemli bir etken olan yenilikçilik, aynı zamanda bir performans göstergesi olarak ele alınmakta ve işletmelerin gündeminde giderek daha fazla yer almaktadır.

Günümüzün başarılı işletmeleri, müşteri yönlü politikalar ve yenilikçilik politikaları geliştiren ve bunları izleyen işletmelerdir. Günümüz müşterisi; bilgili, bilinçli ve ne istediğini bilen kişilerden oluşmaktadır. Bu müşterileri ikna etmek ve satın almada bulunmalarını sağlamak, her geçen gün zorlaşmaktadır. Bu durum, pazar yönlü ve yenilikçi uygulamaları ve bu konuda yapılan araştırmaları her geçen gün daha önemli hale getirmektedir.

Tüm bunlara bağlı olarak bu araştırmanın amacı, mikro ölçekli girişimlerde müşteri yönlülük, rakip yönlülük ve fonksiyonlar arası koordinasyon yönünde ele alınan pazar yönlülük bileşenlerinin ve genel işletmecilik sorunlarının yenilik performansı üzerinde etkisini ölçmektir.

\section{Mikro Girişimler}

Mikro girişimler, gelişmiş ya da gelişmekte olan pek çok ülkede ekonomik yapının önemli bir unsurudur. Çeşitli araştırmacılar, mikro işletmelerin gelişmiş ve gelişmekte olan ülkelerde ekonomik kalkınmanın temel taşlarından birini oluşturduğunu düşünmektedir (Fumo ve Jabbour 2011; Stel vd. 2005; van Praag ve Versloot, 2007; Karadeniz ve Göçer, 2007; Acs vd. 2008; Beck vd. 2005). Çoğu ekonomik raporda, 10'dan az çalışana sahip olan işletmeler olarak tanımlanan mikro işletmeler, sıklıkla yeni iş yaratmanın önemli bir kaynağı olarak ele alınır (Sheikh vd. 2002; Edmiston, 2007). Mikro girişimlerin küçük ve orta ölçekli işletmelere oldukça benzer yönleri 
olmakla birlikte, mikro girişimleri küçük ve orta ölçekli işletmelerden çeşitli açılardan farklı kılan özellikleri de bulunmaktadır.

Mikro girişimler, ekonomideki sayısal çoğunluklarının ve istihdama katkılarının yanı sıra; ekonomik, toplumsal ve bölgesel kalkınmaya katkı sağlama, ekonomiye dinamizm kazandırma, esneklik, yenilikleri teşvik etme, rekabeti koruma ve yabancılaşmayı önleme gibi konularda da katkı sağlamaktadır (Yörük ve Ban, 2003).

Küreselleşen dünyada mikro girişimler, rekabetçi bir biçimde yaşamlarını sürdürebilmek için; hız, teknoloji ve yenilikçilik unsurlarını kapsamına alan bir mücadeleyi dinamik bir süreçte yaşamaktadır. Mikro işletmeler müşteriyle daha yakın olmaları nedeniyle, müşteri ihtiyaçlarını daha kolay araştırıp keşfetmekte ve yenilikler peşinde koşabilmektedir. Aynı zamanda, esnek yapıları sayesinde yeniliklere kolayca uyum sağlamaları, daha büyük işletmelere göre daha kolay olmaktadır (Sevim, 2013).

\section{Pazar Yönlülük ve İşletme Performansı}

Pazar yönlülük ile ilgili çalışmalar Amerika'da başlamış olmakla birlikte, günümüzde dünyanın pek çok farklı bölgesinde devam etmektedir. İşletmecilik yaşamındaki değişmeler ve müşterilerin giderek artan beklentileri doğrultusunda, işletmelerin rekabet güçlerini artırmalarında pazar yönlülüğün önemi her geçen gün artmaktadir.

Pazar yönlülük ile ilgili literatürde yer alan çalışmalar dört alanda yoğunlaşmaktadır. Bunlar aşağıdaki gibi sıralanabilir (Karahan ve Özçiftçi, 2008; Harris 2000);

1. Pazar yönlülüğün felsefi temelinin analizinde teoriye ağırlık veren çalışmalar (Kotler ve Levy, 1969; Mc Namara, 1972; Hirschman, 1983; Webster, 1994).

2. Pazar yönlülüğü tanımlama ve uygulanabilir hale getirmeye odaklı çalışmalar (Kohli ve Jaworski, 1990; Narver ve Slater, 1990; Deng ve Dart, 1994; Cadogan ve Diamantopoulos, 1995; Despande ve Farley, 1998).

3. Pazar yönlülük ile performans arasındaki ilişkileri farklı ülke ve çevre şartlarında araştıran çalışmalar (Pitt vd. 1996; Selnes vd. 1996; Slater ve Narver, 1994; Greenley, 1995).

4. Gelişen pazar yönlülüğün olası engellerini araştıran çalışmalar (Felton, 1959; Lear, 1963; Messikomer, 1987; Jaworski ve Kohli, 1993; Haris, 1998).

1990'lı y1llardan sonra, özellikle Jaworski ve Kohli (1990) ile Narver ve Slater (1990) tarafından önerilen pazar yönlülük yapısı, çeşitli araştırmalara konu olmuştur. Pazar yönlülük kavramı, Jaworski ve Kohli (1990) tarafından, "örgüt genelinde müşterilerin mevcut ve gelecekteki ihtiyaçlarına ilişkin pazar bilgisi üretilmesi, üretilen bu bilginin bölümler arasında yayllması ve tüm örgüt genelinde bu bilgiye bağhl olarak hareket edilmesi" şeklinde tanımlanmıştır.

Narver ve Slater (1990) ise, pazar yönlülüğü "alıcllar için en yüksek değeri ve dolayısıyla işletme açısından sürekli olarak, en üstün performansı yaratmak için gerekli olan davranışları en etkin ve etkili biçimde üreten örgüt kültürü” olarak tanımlamıştır. Pazar yönlülük ayrıca, söz konusu yazarlar tarafından işletme performansının önemli bir destekçisi olarak tanımlanmaktadır (Jaworski ve Kohli, 1993; Narver ve Slater, 1990). 
Narver ve Slater (1990), pazar yönlülüğün; müşteri yönlülük, rakip yönlülük ve fonksiyonlar arası koordinasyon olmak üzere üç davranışsal bileşenden oluştuğunu ileri sürmüştür. Narver ve Slater (1990) bu üç bileşeni şu şekilde tanımlamıştır:

• Müşteri yönlülük: Hedef müşterilere sürekli olarak üstün değer sağlayabilmek için müşterileri anlamak.

- Rakip yönlülük: İşletme açısından kilit öneme sahip mevcut ve potansiyel rakiplerin, kısa dönemdeki güçlü ve zayıf yönleri ile uzun dönemdeki yetenek ve stratejilerinin anlamak.

- Fonksiyonlar arası koordinasyon: Hedef pazarda en yüksek değeri yaratmak amacıyla, işletme fonksiyonlarının birbiri ile iletişim sağlamasını, uyumlu olmasını ve bilgi alışverişinde bulunmasını ve kaynakların birimler arasında koordineli biçimde kullanılmasını sağlamak.

Pazar yönlülüğü, pazarlama kavramının uygulanmasını kapsayan faaliyetler bütünü olarak tanımlayan Jaworski ve Kohli (1993) ise, pazar yönlülüğün işletme faaliyetlerinin üç kapsamlı kümesinden oluştuğunu ileri sürmüştür: Bunlar aşağıdaki şekilde suralanabilir:

- Müşteri ihtiyaçlarına ilişkin mevcut ve geleceğe yönelik olarak pazar bilgisinin toplanmasi,

- Birimler arası bilginin yayılması,

- Tepkinin oluşturulması.

Pazar yönlülükle ilgili literatürdeki çalışmaların çoğu, küçük ve mikro ölçekli işletmelerde, pazar yönlülüğün büyük ölçüde, müşteri yönlü olmak olduğunu ortaya koymaktadır (Jaworski ve Kohli, 1993; Narver ve Slater, 1990).

Pazar yönlülüğün işletme performansı üzerindeki etkisine ilişkin çalışmalar, 1990'lı yıllardan itibaren yapılmaya başlanmıştır. Literatürde, pazar yönlülük ile işletme performansı arasında pozitif yönde ilişki olduğunu gösteren çeşitli çalışmalar bulunmaktadır (Desphande vd. 1993; Robicheaux ve Coleman, 1994; Abramson ve Ai, 1997; Yau vd. 2000; Harrison-Walker, 2001; Spillan vd. 2009; Nikoomaram ve Maatoofi, 2011). Genellikle büyük ölçekli işletmelere yönelik olarak yapılan bu çalışmalar, son dönemlerde küçük ve orta ölçekli işletmelere yönelik olarak da gerçekleştirilmektedir (Hogarth-Scott vd. 1996; Pelham ve Wilson, 1996).

Nikoomaram ve Maatoofi, (2011), pazar yönlü işletmelerin müşterilerini daha değerli gördügünü ve bu nedenle, daha yüksek örgütsel performansa ve rekabet gücüne sahip olduklarını iddia etmektedir. Spillan ve diğerleri (2009) ise, pazar yönlülük ve işletme performansı arasındaki ilişkiyi etkileyen çeşitli faktörler üzerine odaklanmış ve bu faktörlerin; endüstri özellikleri, müşteri özellikleri ve performans ölçme yöntemleri olduğunu ileri sürmüştür.

Jaworski ve Kohli (1993), aynı zamanda pazar yönlülüğün işletme performansı üzerindeki etkisinin, çevresel koşullara bağlı olarak güçlü ya da zayıf olabileceğini iddia etmektedir (Şekil 1). Diğer taraftan çeşitli araştırmacılar, KOBİ'lerde pazar yönlülük ve becerilerinin olmamasının, bu işletmelerde düşük performans ve yüksek işletme başarısızlığı riskine yol açtığını ortaya koymuşlardır (Jones ve Rowley, 2011; Alpkan vd. 2007; Blankson ve Stokes, 2002; Brooksbank vd. 2004; Hill ve Blois, 1987; Huang ve Brown, 1999; McCartan-Quinn ve Carson, 2003). 


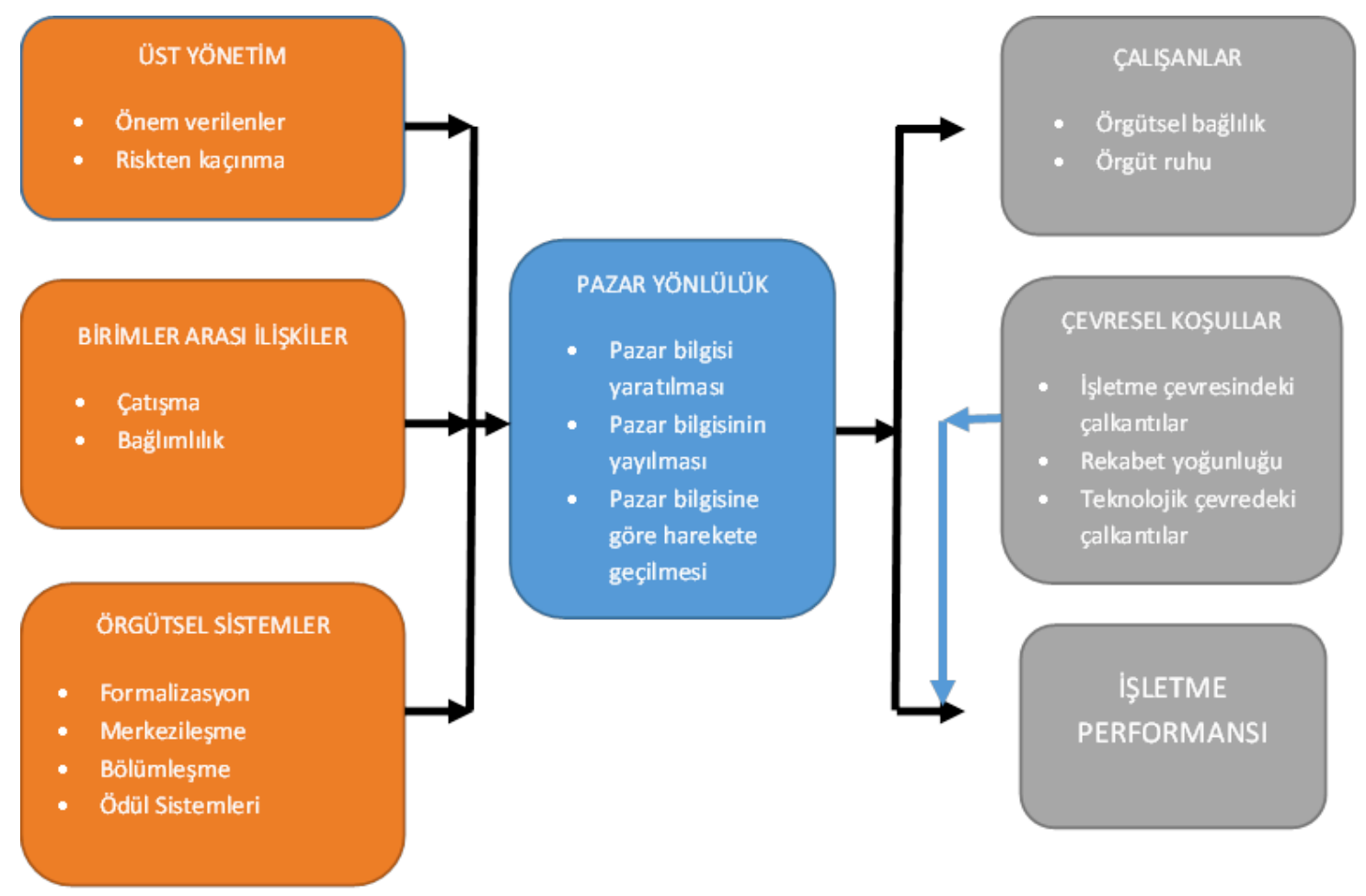

\section{Şekil 1. Pazar Yönlülük Yapısı ve İşletme Performansına Etkisi}

Kaynak: Jaworski ve Kohli, 1993, s. 55.

\section{Mikro Girişimlerin Başarı Faktörleri ve Yaşadıkları Sorunlar}

Küreselleşen dünyada, mikro girişimler rekabetçi bir biçimde yaşamlarını sürdürebilmek için; hız, teknoloji ve yenilikçilik faktörleri açısından bir mücadele sürdürmekte; müşteriyle daha yakın olmaları nedeniyle, müşteri ihtiyaçlarını daha kolay araştırıp keşfetmekte ve yenilikleri hayata geçirme şansına sahip olmaktadır (Sevim, 2013). Öte yandan, küçük ölçekli işletmelerin \%20'si, faaliyete başladıklarından bir y1l sonra, \%66'sı ise, faaliyete başladıklarından sonra altı yıl içinde başarısız olup yaşamları sona ermektedir (Franco ve Haase, 2010).

Küçük ölçekli işletmelerin, dolayısıyla mikro girişimlerin bu kadar büyük bölümünün kısa bir süre içinde başarısız olmalarının nedenlerini inceleyen çeşitli araştırmalar vardır (Mead ve Liedholm, 1998; Katwalo, 2010; Franco ve Haase, 2010; Chittithaworn vd. 2011; Philip, 2011).

Küçük işletmelerin yaşadıkları sorunların en önemlisi, nakit sıkıntısı olup bununla doğrudan ilişkili bir diğer önemli sorun da, yenilik yapma becerisidir (Franco ve Haase, 2010). Yenilikçilik becerisi ve dolayısıyla işletmeye rekabet üstünlüğü yaratacak beceriler geliştirmek; araştırma yapma, işletme dışı bilgi kaynaklarına ve teknolojiye ulaşma gibi koşulları da beraberinde getirmektedir. Finansal kaynak sıkıntıları ve yenilikçilik performansının düşük olması, küçük işletmelerin rekabetçilik düzeylerini ve nihayetinde varlıklarını sürdürmeleri önündeki en önemli engellerdir (Franco ve Haase, 2010).

Küçük işletmelerin yaşadığı sorunlardan bir diğeri, işbirliği ve ortaklık kurma eksikliğidir (Franco ve Haase, 2010; Philip, 2011). İşbirliğgi ve ortaklık kurma becerisinin yüksek olması, küçük girişimlerde işletme performansını olumlu yönde 
etkileyen faktörlerden biridir (Philip, 2011). Ancak genel olarak; işletme büyüklüğü, yerel nitelikte veya sınırlı faaliyet alanı, sahip odaklı yönetim biçimi gibi nedenlere bağlı olarak, işbirliği ve ortaklık kurma konularındaki yetersizlikler, küçük girişimlerin başarısını olumsuz olarak etkilemektedir (Franco ve Haase, 2010).

Küçük işletmelerin, dolayısıyla mikro girişimlerin yaşadığ diğeri, rekabetle başa çıkma konusunda sıkıntı yaşanmasıdır (Mead ve Liedholm, 1998; Katwalo, 2010). Özellikle mikro girişimler söz konusu olduğunda, birbiriyle birebir aynı ürün veya hizmetleri sunan, benzer bölgelere veya müşterilere hizmet veren rakipler, mikro işletmelerin varlıklarını sürdürmeleri önünde önemli engeller yarabilmekte, yeni rakiplerin pazara girmesi mikro işletmelerin satış ve kar düzeylerini kısa bir süre içinde olumsuz yönde etkileyebilmektedir. Buna bağlı olarak, küçük ve mikro işletmelerin başarılı olabilmesi, rakiplerine kıyasla müşterilerinin istek ve ihtiyaçlarını daha doğru şekilde anlamalarını, bunlara daha kaliteli ürün veya hizmet sunmalarına bağlı hale gelmektedir (Katwalo, 2010). Bununla birlikte, bilgi ve teknolojiye erişim ve yenilikçilik performansı açısından sorun yaşayan küçük işletmelerin bu koşulları sağlamaları daha da zorlaşmaktadır (Franco ve Haase, 2010). Bahsedilen bu faktörler, bu çalışmada mikro girişimlerin yaşadığı genel işletmecilik sorunları olarak ele alınmıştır.

\section{Yenilik performansı}

Yenilikçilik teorisinin öncülüğünü yapan Schumpeter'a (1912) göre yenilik, şu beş kavramdan herhangi birisini içerebilir: (1) Pazara yeni bir ürün sunmak, (2) Yeni bir üretim yöntemi bulmak, (3) Yeni bir pazara açılmak, (4) Yeni bir hammadde veya ara mal arz kaynağını ele geçirmek, (5) Yeni bir örgütlenme biçimini uygulamak. Schumpeter'dan sonra, yenilikçiliğge ilişkin çalışmalar artmış ve yenilik kavramına ilişkin çok sayıda tanım yapılmıştır. Günümüzde yenilikçilik, birçok işletmenin rekabet üstünlüğünün gizli kaynağı durumundadır.

1960'l1 yıllara kadar daha çok teknolojik değişim ve gelişmelerle ilişkilendirilen yenilik kavramı, 1960'lardan itibaren psikolojik ve sosya- kültürel açılardan da ele alınıp incelenmeye ve tüketici davranışları ile ilişkilendirilmeye başlamıştır (Everett, 1983; Rogers, 2003). Peters ve Waterman (1982) yeniliği, "çevredeki herhangi bir değişime yant verme becerisi ve yeni ürün geliştirme faaliyeti” olarak tanımlarken; Kotler (2003) ise yeniliği, "bir kişi tarafindan yeni olarak algllanan ürün, hizmet ve fikir" olarak tanımlamıştır. OECD Oslo El Kitabında (2005) yenilikçilik kavramı, "işletmecilik uygulamalarında, işyeri örgütlenmesinde ya da örgüt dişı iliş̧kilerde yeni veya önemli ölçüde geliştirilmiş bir ürün (mal veya hizmet) ya da yeni bir süreç veyahut yeni bir pazarlama yöntemi ya da yeni bir örgütlenme yöntemi kullanmak" şeklinde tanımlanmıştır. Bu tanıma göre; ürün, süreç, pazarlama ve örgütsel olmak üzere dört çeşit yenilikten söz edilebilir.

Literatürde yenilik ile ilgili yapılan çalışmalar, yeniliği üç ayrı şekilde kategorize etmektedir; (1) Teknik ve yönetsel yenilik, (2) Ürün ve süreç yeniliği ve (3) Radikal ve tedrici (kademeli) yenilik (Peçen ve Kaya, 2013).

Son dönemlerde, değişim ve yenilikçiliğin yöneticiler için önemini ortaya koyan çok sayıda çalışmaya rastlanmaktadır (Caldwell ve O'Reillly, 2003). İşletmeler değişen çevre koşullarına uyum sağlayabilmek, örgütsel performanslarını geliştirebilmek ve 
sürdürebilmek için sürekli yenilik yapmak eğilimindedir (Hagedoorn ve Cloodt, 2003; Damanpour vd. 2009).

Yenilikçilik yukarıdaki tanımlarda da ifade edildiği gibi, yalnızca ürün ve süreçle ilgili bir kavram olmayıp, aynı zamanda pazarlama ve örgütlenme ile de ilgili bir kavramdır. Akova vd. (1998) bu durumu, yenilikçilik sürecindeki en ciddi riskin yeni ürün ve hizmetlerin geliştirilmesinden değil, değişen müşteri taleplerinin hızına ayak uyduramamaktan kaynaklanması şeklinde ifade etmektedir. Aynı zamanda, girişimcilik de yalnızca yeni ürünler veya yeni fikirler ortaya koyan ve uygulayan bir süreç olarak değerlendirilmemelidir. Ayrıca, yenilikçi pazarlama uygulayan bir süreç olarak da değerlendirilmelidir. Bu da, yalnızca yeni ürünlerde değil, tüm pazarlama faaliyetlerinde yeniliğin ön planda olmasını gerektirmektedir. Bu düşünce, girişimciliğin firsat yönlü bir faaliyet olduğuna ve girişimciliğin yenilikçilik işlevine dikkat çekmektedir (Blenker, 2000). Drucker'a (1985) göre girişimci; değişim arayışında olan, değişime ayak uyduran ve değişimi kendi yararına kullanan kişidir.

Rekabet gücünün artırılmasında önemli bir etken olan yenilikçilik, aynı zamanda bir performans göstergesi olarak ele alınmakta ve işletmelerin gündeminde giderek daha fazla yer almaktadır. Yenilik ve işletme performansı arasındaki ilişkiyi araştıran çalışmaların sayısı her geçen gün artmaktadır (Cooper ve Kleinschmidt, 1987; Lee ve Miller, 1999; Kivimöki vd. 2000; Cooper, 2000; Calantone vd. 2002; Hagedoorn ve Cloodt, 2003; Manzanti vd. 2006; Oke, 2007; Günday, 2007, Jimenez ve Valle, 2011). Günümüzde hızla değişen müşteri ihtiyaçlarını karş1layabilmek, büyük ölçüde işletmenin yenilikçilik performansına bağlı bulunmaktadır.

İşletmeleri yenilikçiliğe teşvik eden işletme içi ve dışı birçok faktör, çeşitli araştırmalar sonucunda belirlemiştir. Wang ve Costello (2009), işletmeleri yenilikçiliğe teşvik eden faktörleri bireysel, örgütsel ve çevresel faktörler olarak üç başlık altında toplamıştır.

Son zamanlarda, pazar yönlülüğün yenilikçilik üzerinde pozitif etkisi olduğunu ortaya koyan çeşitli çalışmalar yapılmıştır (Bulut vd. 2009; Jimenez-Zargo vd. 2011; Tung, 2012; Zortea-Johnston vd., 2011; Erdil vd. 2013). Cengiz ve diğerlerine (2005) göre, yeni ürün geliştirmede; üst yönetimin desteği, teknoloji ve bilgi yönetimi en etkili faktörlerdir ve yenilikçilik ile pazar yönlülük arasında güçlü bir ilişki bulunmaktadır.

\section{Türkiye'de Mikro Ölçekli Girişimler ve Yenilik Faaliyetleri}

Mikro ölçekli girişimler genel olarak; çalışan sayısının az olması, düşük gelir elde etme, dar ve yerel bir çevrede faaliyet gösterme, işletme sahibi tarafından yönetilme ve kendi kendine istihdam yaratma gibi temel özellikler taşımaktadır.

Türkiye İstatistik Kurumu (TÜİK) 2014 yılı verilerine göre, Türkiye'de KOBİ'ler toplam girişimlerin \% 99,8'ini oluşturmaktadır. (http://www.tuik.gov.tr/PreHaber Bultenleri.do?id=21864). 1-9 çalışana sahip mikro ölçekli işletmeler ise, toplamın \%95,62'sini teşkil etmektedir. KOBI'lerin \%82'si hizmetler ve ticaret, \%13'ü ise imalat sanayi sektöründe faaliyet göstermektedir (KOBİ Stratejisi ve Eylem Planı 2011-2013).

TÜİK tarafından gerçekleştirilen Yenilik araştırması sonuçlarına göre 2012-2014 yıllarını kapsayan üç yıllık dönemde 10 ve daha fazla çalışanı olan girişimlerin \%51,3’ü yenilik faaliyetinde bulunmuş; çalışan sayısı 10-249 olan KOBİ'lerde ise bu oran \%50,8 olmuştur. Aynı dönemde KOBİ'lerin \%37,4'ü ürün ve/veya süreç yeniliği; \%40,5'i ise 
organizasyon ve/veya pazarlama yeniliği gerçekleştirmiştir (http://www.tuik.gov.tr/ PreHaberBultenleri.do?id=21864).

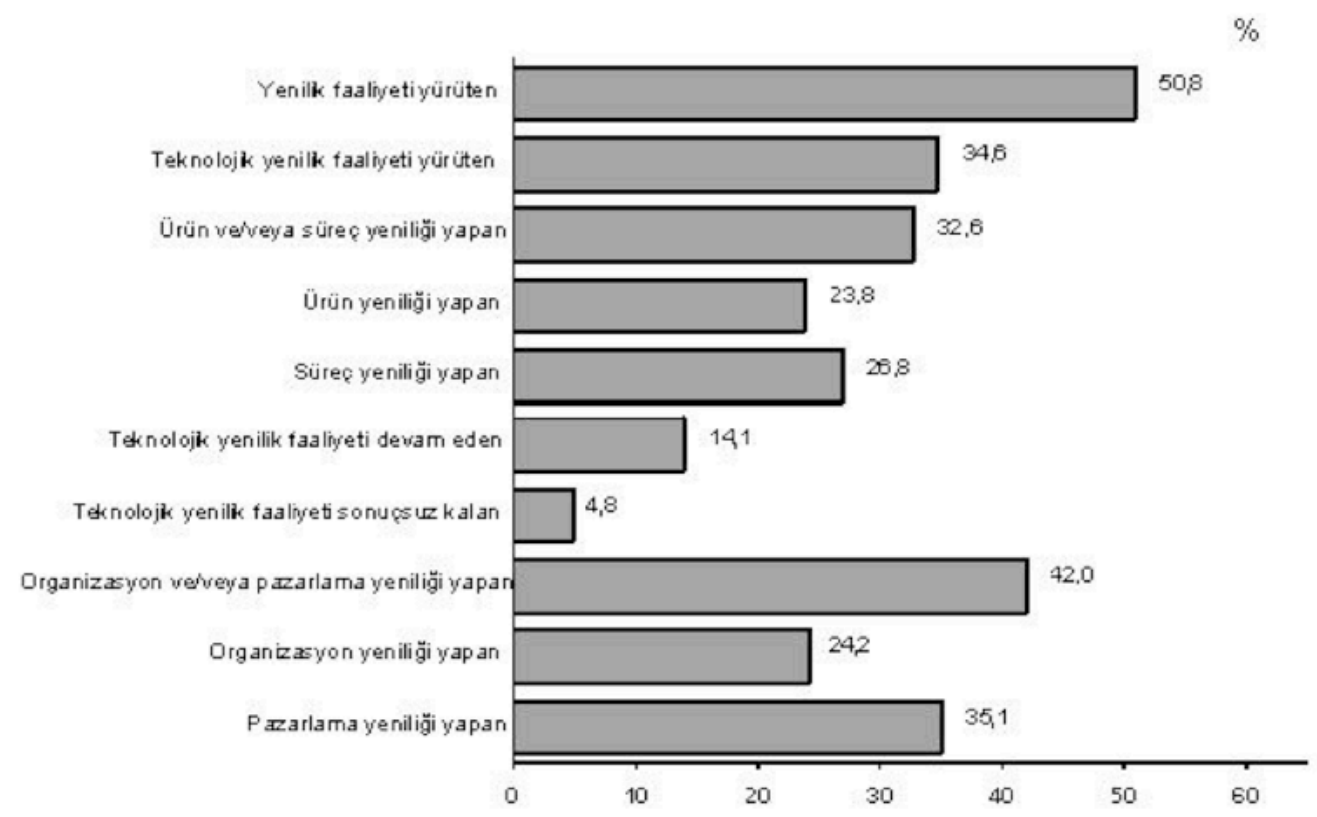

Şekil 2. KOBİ'lerde Yenilik Faaliyetleri (2008-2010)

Kaynak: http://www.tuik.gov.tr

Yenilik performansı, bir ülkenin uluslararası rekabet gücünü artırmasında önemli kriterlerden birini oluşturmaktadır (http://www.tsv2023.org). Bu açıdan, gelişmekte olan bir ülke olan Türkiye'de işletmelerin özellikle de mikro işletmelerin yenilik performansını artırması için ulusal politika, strateji ve desteklere ihtiyaç bulunmaktadır.

\section{Araştırmanın Yöntemi}

$\mathrm{Bu}$ araştırma, Eskişehir'de faaliyet gösteren esnaf ve sanatkârların sosyoekonomik yapısı, temel sorunları ve sorunlarına çözüm önerileri bulmaya yönelik araştırma projesinin bir parçasını oluşturmaktadır. Bu araştırma, Eskişehir ili özelinde mikro girişimlere ilişkin olarak yapılan ilk kapsamlı çalışma olması açısından önem taşımaktadır.

Araştırma projesinin bulguları, Eskişehir esnaf ve sanatkârlarının demografik özellikleri ve sorunları, bu sorunların nedenleri, Eskişehir ilinin esnaf ve sanatkârlara sağladığı avantajlar, meslek odalarından beklentiler ve kaynak ihtiyacı ve finansmanda kullanılan yöntemlerin değerlendirilmesi olmak üzere altı başlık altında incelenmiştir. $\mathrm{Bu}$ araştırmanın bulguları ise, ana proje kapsamında değerlendirmeye alınmamış olup yalnızca bu çalışmada değerlendirilmiştir.

$\mathrm{Bu}$ çalışma kapsamında ele alınan değişkenler ve araştırmanın modeli, aşağıda Şekil 3'te sunulmaktadır. Bu araştırmada pazar yönlülügü oluşturan müşteri yönlülük, rakip yönlülük ve fonksiyonlar arası koordinasyon boyutlarının ve mikro işletmelerin yaşadığı genel işletmecilik sorunlarının yenilik performansı üzerindeki etkisi incelenmektedir. 


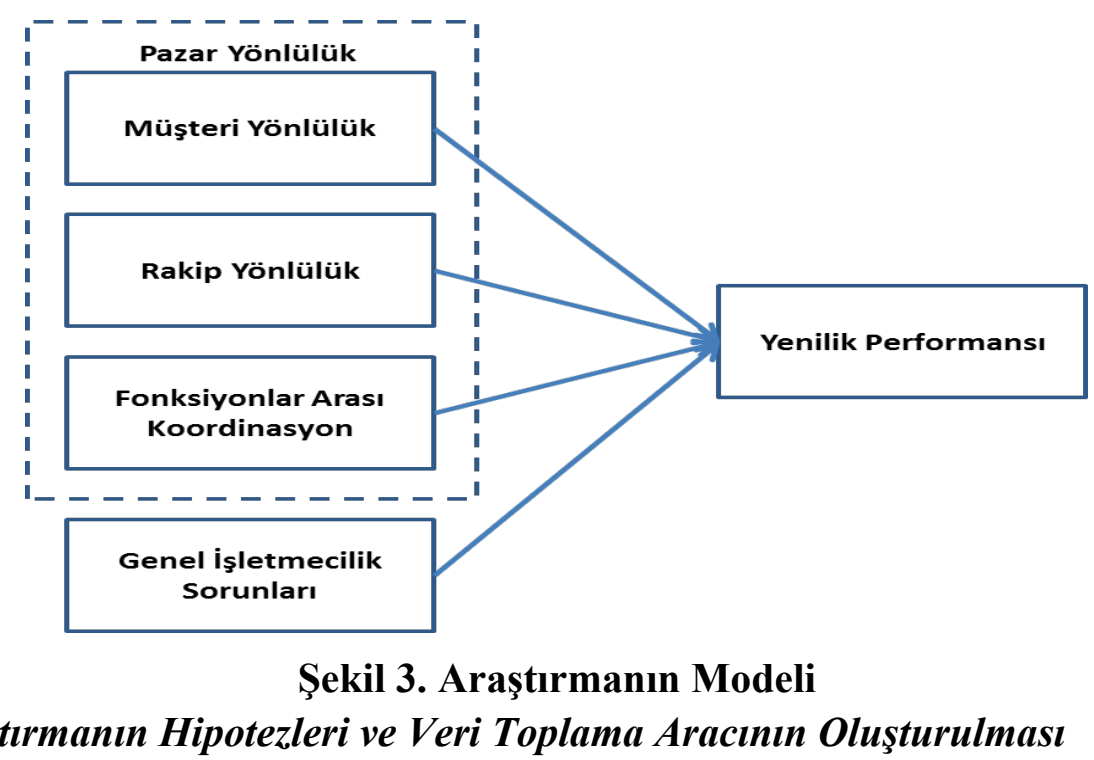

\section{Araştırmanın Hipotezleri ve Veri Toplama Aracının Oluşturulması}

Araştırmanın amacına bağlı olarak geliştirilen, araştırma modeli doğrultusunda çalışmada test edilen araştırma hipotezleri şöyledir:

$\mathbf{H}_{1 \mathbf{a}}$ : Pazar yönlülüğün müşteri yönlülük bileşeni ile mikro işletmelerin yenilik performansı arasında pozitif bir ilişki vardır.

$\mathbf{H}_{1 \mathbf{b}}$ : Pazar yönlülüğün rakip yönlülük bileşeni ile mikro işletmelerin yenilik performansı arasında pozitif bir ilişki vardır.

$\mathbf{H}_{1 \mathbf{1}}$ : Fonksiyonlar arası koordinasyon bileşeni ile mikro işletmelerin yenilik performansı arasında pozitif bir ilişki vardır.

$\mathbf{H}_{2}$ : Mikro işletmelerin yaşadığı genel işletmecilik sorunları ile yenilik performansları arasında negatif bir ilişki vardır.

$\mathbf{H}_{3 \mathbf{a}}$ : Pazar yönlülüğün müşteri yönlülük bileşeninin mikro işletmelerin yenilik performansı üzerinde pozitif şekilde etkisi vardır.

$\mathbf{H}_{\mathbf{3 b}}$ : Pazar yönlülüğün rakip yönlülük bileşeninin mikro işletmelerin yenilik performansı üzerinde pozitif şekilde etkisi vardır.

$\mathbf{H}_{\mathbf{3}}$ : Pazar yönlülüğün fonksiyonlar arası koordinasyon bileşeninin mikro işletmelerin yenilik performansı üzerinde pozitif şekilde etkisi vardır.

$\mathbf{H}_{4}$ : Mikro işletmelerin yaşadığ 1 genel işletmecilik sorunlarının yenilik performansları üzerinde negatif şekilde etkisi vardır.

Araştırma kapsamında ele alınan değişkenlere ilişkin veri toplanabilmesi amacıyla, mevcut literatür taranmış ve değişkenlerle ilgili geliştirilmiş ölçümleme araçlarına ulaşılmıştır. Pazar yönlülüğün ölçümü amacıyla, Jaworski, Kohli ve Kumar (1993) MARKOR ölçeğini, Narver ve Slater (1990) ise MKTOR ölçeğini geliştirmiştir. Bu iki ölçek, literatürde pazar yönlülüğü ölçmede yaygın olarak kullanılan iki ölçektir. İşletme faaliyetlerine odaklanan MKTOR ölçeği, pazar bilgisini ölçmede müşteri ve rakip bilgisi ile birlikte, iş çevresini ve düzenleyici unsurları da dikkate almaktadır. MKTOR ölçeği ise, eylemden daha çok kültüre yönelik unsurları içermekte ve yalnızca müşteri ve rakiplere dikkat çekerek, diş unsurlara odaklanmaktadır. MKTOR ölçeği; Jaworski ve Kohli tarafından, rakip ve müşterilere odaklanarak diğer unsurları (özellikle teknoloji vb.) göz ardı ettiği, bilgi toplama ve örgüt içinde yayılmasının hızını belirlemediği ve pazar yönlülüğü açıklayan faaliyet ve davranışları göz ardı ettiği konularında eleştirilmiştir. Pazar yönlülüğün ölçülmesi için daha sonra Deshpande vd. 
(1993), Ruekert (1992), Deng ve Dart (1994), Gray vd. (1998), Smith ve Smith (2007), Carr ve Lopez (2007), Alhakimi ve Baharun (2009) gibi yazarlar da MARKOR ve MKTOR ölçeklerini sentez ederek ölçekler geliştirmiştir (Zengin ve Ekber, 2012).

$\mathrm{Bu}$ çalışmada pazar yönlülük uygulamalarının ölçümünde, Narver ve Slater (1990)'in oluşturduğu müşteri ve rakip odaklılık ile fonksiyonlar arası koordinasyonu kapsayan üç boyutlu ölçek kullanılmış ve boyutlar toplam 14 soru ile ölçülmüştür. Ancak, MKTOR ölçeği esas olarak büyük işletmelerin pazar yönlülügünü ölçmek amacıyla geliştirildiği için, mikro işletmelerden uygun veri toplamak amacıyla, mikro işletmelere uygulanabilecek şekilde uyarlanmıştır.

Literatürde küçük ölçekli işletmelerin başarı faktörleri ve başarı önündeki engelleri ele alan çalışmalardan (Mead ve Liedholm, 1998; Katwalo, 2010; Franco ve Haase, 2010; Chittithaworn vd. 2011; Philip, 2011) yola çıkılarak, bu çalışmanın parçası olduğu araştırma projesi kapsamında, mikro girişimleri oluşturan esnaf ve sanatkârların sorunlarını doğru belirleyebilmek ve veri toplama aracındaki soruları amaca uygun olarak hazırlayabilmek açısından, mikro ölçekli işletmelerin temsilcileri olan esnaf odaları yöneticileri ile arama görüşmeleri yapılmıştır. 250 kişinin katılımıyla gerçekleştirilen bu toplantının çıktıları, Eskişehir Esnaf ve Sanatkârlar Odası Başkan ve yöneticileri ile paylaşılmıştır. Mikro girişimlerin yaşadığı genel işletmecilik sorunlarını ölçümlemek için kullanılan sorular, bu sürecin sonunda belirlenmiştir.

Yenilik performansını ölçmek için ise, çeşitli yazarların çalışmalarının incelenmesi sonucunda oluşturulan 6 maddeli ölçekten yararlanılmıştır (Neely ve Hii,1998, Meeus ve Oerlemans, 2000, Calantone vd. 2002, Hagedorn ve Cloodt, 2003). Pazar yönlülüğün, mikro işletmelerin yaşadığı genel sorunların ve yenilik performansının ölçümünde, 1- Kesinlikle Katılmıyorum, 2- Katılmıyorum, 3- Ne Katılıyorum Ne Katılmıyorum, 4- Katılıyorum ve 5- Kesinlikle Katılıyorum şeklindeki 5'li Likert ölçeği kullanılmıştır.

Bunların yanı sıra, veri toplama aracında mikro işletmelerin çeşitli özelliklerini öğrenmeyi amaçlayan işletme sahibi ve kuruluşa ilişkin çeşitli sorular yer almıştır.

\section{Araştırmanın Ana Kütlesi, Örneklemi ve Veri Toplama Süreci}

Araştırma kapsamında yukarıda da belirtildiği gibi, esnaf odaları yöneticileri ile yapılan arama görüşmeleri sonucunda hazırlanan anket soruları, Eskişehir Esnaf ve Sanatkârlar Odası Başkan ve yöneticilerinin görüşleri alındıktan sonra pilot uygulamaya hazır hale getirilmiştir. Anket formu 120 kişilik bir esnaf grubuna pilot olarak uygulandıktan sonra, forma son hali verilmiştir.

Anketlerin, Eskişehir ilinde faaliyet gösteren ve esnaf odalarına kayıtlı olan toplam 16269 esnaf ve sanatkârın \% 20'sine uygulanması hedeflenmiştir. Anketler, anketörlerin yardımı ile yüz yüze gerçekleştirilmiş, ancak saha çalışması sonucunda elde edilen anket sayısı araştırmaya katılım düzeyine bağlı olarak 1769 olarak gerçekleşmiştir.

\section{Araştırmanın Veri Analizi ve Bulguları}

Araştırmaya katılan mikro girişimlerden elde edilen betimleyici veriler ve hipotez testleri için gereken istatistiksel analizler, PASW (SPSS) 18 İstatistiksel Analiz paket programı ile gerçekleştirilmiştir. Araştırmaya katılan mikro girişimlerin ve sahiplerinin özellikleri Tablo 1'de sunulmaktadır.

Tablo 1'den de görüleceği üzere, araştırmaya katılan mikro işletmelerin \%28'inde herhangi bir çalışan istihdam edilmemektedir. Bunun yanında, mikro işletmelerin 
\%46'sı 1-4 çalışan, \%13,2'si 5-8 çalışan istihdam ederken, 9'dan fazla çalışan istihdam eden işletmelerin oranı yalnızca \%5,7'dir. Söz konusu mikro girişimlerin \%29'unun cirosunun 30 bin TL ve altında; \%12'sinin 30 ila 45 bin TL arasında; yaklaşık \%26'sının ise 45 bin TL'nin üzerinde olduğu görülmektedir.

Araştırmaya katılan mikro işletmelerin faaliyet süreleri incelendiğinde, yaklaşık \%33'ünün 10 yıl veya daha kısa bir süreden bu yana faaliyet gösterdiği, \%37,5'inin 1020 yıllık bir geçmişi olduğu, 20 yıldan uzun süredir faaliyet gösterenlerin oranının ise \%26 düzeyinde olduğu görülmektedir. Bu işletmelerin faaliyet alanları incelendiğinde, \%28,4'ünün bakkal-bayi, firın, kafe-restoran türlerindeki ve su ve yaş meyve-sebze satışı gerçekleştiren gıda perakendecileri olduğu; \%26'sının minibüs ve diğer ticari araçlarla hizmet sağlayan ulaşım alanındaki işletmeler olduğu; \%21,4'ünün ise marangozluk, tornacılık, demircilik vb. imalat ve satış işletmeleri olduğu belirlenmiştir. Bunların yanı sıra, araştırmaya katılan mikro işletmelerin dörtte üçünün tek şube ile faaliyet gösterdiği tespit edilmiştir.

Tablo 1. Araştırmaya Katılan Mikro İşletmelerin ve Sahiplerinin Demografik Özellikleri

\begin{tabular}{|c|c|c|c|}
\hline İşletme Sahibinin Cinsiyeti & $\%$ & İşletmenin Çalışan Sayısı & $\%$ \\
\hline Kadın & 8,0 & Çalışan yok & 28,0 \\
\hline Erkek & 89,4 & 1-4 kişi & 46,0 \\
\hline \multirow[t]{2}{*}{ Cevap vermeyenler } & 2,6 & 5-8 kişi & 13,2 \\
\hline & & 9 kişi ve üzeri & 5,7 \\
\hline İşletme Sahibinin Yaşı & $\%$ & Cevap vermeyenler & 7,1 \\
\hline $18-25$ & 4,0 & & \\
\hline $26-33$ & 14,6 & İşletmenin Cirosu & $\%$ \\
\hline $34-41$ & 29,0 & 15,000 TL'ye kadar & 25,6 \\
\hline $42-49$ & 29,4 & $15,001-30,000$ TL aras 1 & 29,0 \\
\hline $50-57$ & 14,0 & $30,001-45,000$ TL aras1 & 12,3 \\
\hline $58-65$ & 5,8 & $45,001-60,000$ TL aras 1 & 6,2 \\
\hline 65 ve üzeri & 1,6 & $60,001-75,000$ TL aras 1 & 3,7 \\
\hline \multirow[t]{2}{*}{ Cevap vermeyenler } & 1,5 & 75,001-90,000 TL aras1 & 5,0 \\
\hline & & $90,001 \mathrm{TL}$ ve üzeri & 10,9 \\
\hline İşletme Sahibinin Eğitimi & $\%$ & Cevap vermeyenler & 7,3 \\
\hline İlköğretim mezunu & 46,3 & & \\
\hline Lise mezunu & 40,1 & İşletmenin Faaliyet Alanı & $\%$ \\
\hline Ön lisans mezunu & 4,3 & Giyim Perakendecileri & 10,7 \\
\hline Lisans mezunu & 5,2 & Gida Perakendecileri & 28,4 \\
\hline Lisansüstü mezunu & 0,2 & Ulaşım & 26,1 \\
\hline Diğer & 1,6 & Berber ve Kuaförler & 9,2 \\
\hline \multirow[t]{2}{*}{ Cevap vermeyenler } & 2,3 & İmalatçılar & 21,4 \\
\hline & & Emlakçılar & 4,1 \\
\hline İşletmenin Faaliyet Süresi & $\%$ & & \\
\hline 5 yıl veya daha az & 13,7 & İşletmenin Şube Sayısı & $\%$ \\
\hline $6-10$ y1l & 19,7 & Tek şubesi olanlar & 75,7 \\
\hline $11-15$ y1l & 21,3 & İki şubesi olanlar & 16,7 \\
\hline $16-20$ y1l & 16,2 & Üç veya daha fazla şubesi olanlar & 5,2 \\
\hline $21-25$ y1l & 9,3 & Cevap vermeyenler & 2,4 \\
\hline 26 yıl veya daha fazla & 16,8 & Toplam & 100,0 \\
\hline Cevap vermeyenler & 3,1 & & \\
\hline Toplam & 100,0 & & \\
\hline
\end{tabular}


Araştırmaya katılan mikro işletmelerin sahiplerinin \%8'inin kadın, \%89'unun ise erkek olduğu; bunların da ağırlıkla ilköğretim ve lise mezunu olduğu görülmektedir.

\section{Tanımlayıcı Analizler ve Hipotez, Testleri}

Araştırmacının amacı doğrultusunda geliştirilen hipotezlerin test edilmesinden önce, araştırma modelinde yer alan değişkenlere ilişkin tanımlayıcı analizler gerçekleştirilmiştir. Bu analizlerin sonuçları, Tablo 2'de sunulmaktadır.

Tablo 2. Açıklayıcı Faktör Analizi Sonuçları ve Güvenilirlik Düzeyleri

\begin{tabular}{|c|c|c|c|c|c|c|}
\hline & Ort. & $S S$. & $\begin{array}{l}\text { Fak. } \\
\text { Yükü }\end{array}$ & $\begin{array}{l}\text { Açık. } \\
\text { Var. }\end{array}$ & KMO & $\alpha$ \\
\hline Pazar Yönlülük & & & & 77,647 & $0,944 * *$ & \\
\hline Müşteri Yönlülük & & & & 10,138 & & 0,807 \\
\hline Bizim için müşteri sadakati önemlidir & 3,984 & 1,118 & 0,858 & & & \\
\hline Müşterilerimize fayda sağlamanın yollarını araştırırız & 3,833 & 1,198 & 0,750 & & & \\
\hline Temel hedefimiz müşteri memnuniyetidir & 4,035 & 1,166 & 0,756 & & & \\
\hline Rakip Yönlülük ve İşletme içi Koord. & & & & 67,509 & & 0,957 \\
\hline Rakiplerin uygulamalarını izler ve hızla yanıt veririz & 3,445 & 1,390 & 0,816 & & & \\
\hline $\begin{array}{l}\text { Rakiplerimizin rekabet güçleri ve rekabet yöntemlerini } \\
\text { tartışırız }\end{array}$ & 3,440 & 1,387 & 0,833 & & & \\
\hline $\begin{array}{l}\text { Avantaja sahip olduğumuz alanlarda rekabet etmeyi } \\
\text { hedefleriz }\end{array}$ & 3,506 & 1,385 & 0,819 & & & \\
\hline $\begin{array}{l}\text { Ben ve tüm çalışanlarım müşterimizin ihtiyaçlarını } \\
\text { karşılamaya çabalarız }\end{array}$ & 3,627 & 1,367 & 0,772 & & & \\
\hline $\begin{array}{l}\text { Müşterilerimiz ile ilgili elde edilen bilgiler çalışanlarımız } \\
\text { arasında paylaşılır }\end{array}$ & 3,458 & 1,398 & 0,865 & & & \\
\hline $\begin{array}{l}\text { Çalışanlarımızın tümü birbirlerinin talep ve ihtiyaçlarına } \\
\text { karşı duyarlıdır ve kaynaklarını diğerleri ile paylaşır }\end{array}$ & 3,393 & 1,401 & 0,861 & & & \\
\hline $\begin{array}{l}\text { İsletme çalışanları arasında rekabet avantajı sağlamaya } \\
\text { yarayan güçlü bir koordinasyon vardır }\end{array}$ & 3,364 & 1,397 & 0,864 & & & \\
\hline Genel İşletmecilik Sorunları & & & & 71,830 & $0,913 * *$ & 0,934 \\
\hline İşbirliği ve ortaklık kültürünün gelişmemiş olması & 2,702 & 1,511 & 0,837 & & & \\
\hline Yenilikçi olamama, yenilikçi fikirler üretememe & 2,761 & 1,516 & 0,872 & & & \\
\hline Üretimde ve hizmette teknolojiden yeterince yararlanamama & 2,854 & 1,494 & 0,890 & & & \\
\hline Bilgi teknolojisi kullanımında yetersizlik & 2,921 & 1,496 & 0,886 & & & \\
\hline Müşteriye özel mal ve hizmet üretimi yapamama & 2,985 & 1,511 & 0,837 & & & \\
\hline $\begin{array}{l}\dot{I}_{c ̧} \text { ve dlş ticarette vizyon (geniş görüşlülük) eksikliğinin } \\
\text { olması }\end{array}$ & 2,862 & 1,513 & 0,805 & & & \\
\hline İ̧letme sayılarının ve rekabetin sürekli artması & 2,675 & 1,516 & 0,801 & & & \\
\hline Yenilik Performansı & & & & 80,704 & $0,925 * *$ & 0,952 \\
\hline Yeni ürünleri rakiplerimizden önce pazara sunarız & 3,303 & 1,419 & 0,888 & & & \\
\hline $\begin{array}{l}\text { Müşterilerimizin gelecekteki ihtiyaçlarını tahmin edebilmek } \\
\text { için gelecekte tüketilebilecek ürünleri tahmin etmeye } \\
\text { çalışırız }\end{array}$ & 3,375 & 1,404 & 0,913 & & & \\
\hline $\begin{array}{l}\text { Yeni ürünler tasarlama konusunda sürekli çalışmalar } \\
\text { yaparız }\end{array}$ & 3,314 & 1,420 & 0,909 & & & \\
\hline $\begin{array}{l}\text { Öncü ve yenilikçi olan müşterilerimizin görüşlerine önem } \\
\text { veririz }\end{array}$ & 3,472 & 1,398 & 0,906 & & & \\
\hline $\begin{array}{l}\text { Mesleğimizdeki yenilikleri ve gelişmeleri sürekli olarak } \\
\text { izleriz }\end{array}$ & 3,535 & 1,381 & 903 & & & \\
\hline Mevcut ürünlerimiz arasında yeni ürünlerin oranı yüksektir & 3,315 & 1,452 & 0,871 & & & \\
\hline
\end{tabular}


Araştırma bulgularının analizinde, 16 soru ve üç boyuttan oluşan pazar yönlülük ölçeği açıklayıcı faktör analizi sonuçlarına göre, müşteri yönlülük boyutundan çapraz faktör yüklerine bağlı olarak 3 maddenin çıkarılması gerekmiştir (3., 5. ve 6. maddeler). Bunun yanı sıra, iki farklı boyut olarak ayrılması beklenen rakip yönlülük ve fonksiyonlar arası koordinasyon boyutları, bir maddenin çıkarılmasından sonra tek bir faktör olarak toplanmıştır. Narver ve Slater'ın (1990) MKTOR ölçeği, büyük işletmelerin elde edilen verilere bağlı olarak geliştirildiği ve literatürde de önemli ölçüde büyük işletmeleri konu alan araştırmalarda kullanıldığı için, mikro girişimler düzeyinde iki boyutun bu şekilde tek bir boyut olarak ortaya çıkması olağan karş1lanabilir.

Gerçekleştirilen açıklayıcı faktör analizi, pazar yönlülük ölçümünde faktör yükleri, açıklanan varyans değerleri ve güvenilirlik (Cronbach's Alpha değerleri) yüksek iki faktör yapısı ortaya çıkarmıştır.

Öte yandan, mikro işletmelerin karşılaştığı genel işletmecilik sorunları, ölçümü ve yenilik performansı ölçeğinin açıklayıcı faktör analizlerinde, herhangi bir sorun yaşanmamış; ölçümler güvenilirliği ve faktör yükleri ve açılanan varyans değerleri yüksek sonuçlar ortaya koymuştur.

Açıklayıcı faktör analizinden sonra, hipotez testlerinin gerçekleştirilebilmesi için öncelikle açıklayıcı faktör analizi sonucu ortaya çıkan boyutlar, diğer bir deyişle araştırma modelini oluşturan değişkenler arasında korelasyon analiz yapılmıştır. Korelasyon analizinin sonuçları Tablo 3'te sunulmaktadır.

Tablo 3. Korelasyon Analizi Sonuçları

\begin{tabular}{|c|c|c|c|c|}
\hline & $\begin{array}{l}\text { Müşteri } \\
\text { Odaklılık }\end{array}$ & $\begin{array}{c}\text { Rakip } \\
\text { Odaklllı ve } \\
\text { İsletme içi } \\
\text { koordinasyon }\end{array}$ & $\begin{array}{c}\text { Genel } \\
\text { Issletmecilik } \\
\text { Sorunlarl }\end{array}$ & $\begin{array}{c}\text { Yenilik } \\
\text { Performansl }\end{array}$ \\
\hline Müşteri Odaklılık & 1 & & & \\
\hline $\begin{array}{l}\text { Rakip Odaklılık ve } \\
\text { Koordinasyon }\end{array}$ & $0,672 * *$ & 1 & & \\
\hline $\begin{array}{l}\text { Genel Issletmecilik } \\
\text { Sorunlart }\end{array}$ & $-0,377 * *$ & $-0,499 * *$ & 1 & \\
\hline Yenilik Performansl & $0,610 * *$ & $0,879 * *$ & $-0,508 * *$ & 1 \\
\hline
\end{tabular}

$* * p<0,01$

Korelasyon analizi sonuçları, açıklayıcı faktör analizi sonucunda belirlenen değişkenlerin Pearson korelasyon katsayılarının, sosyal bilimlerde kabul edilen düzeylere göre orta düzeyde ilişki $\left(r^{2}=0,3-0,6\right)$ ile yüksek düzeyde ilişki $\left(r^{2}>0,6\right)$ arasında değiştiğini göstermektedir (Altunışık vd. 2012). Buna göre, mikro işletmelerin yenilik performansı ile pazar yönlülüğün müşteri yönlülük boyutu ile pozitif yönlü istatistiksel olarak anlamlı bir ilişki $\left(\mathrm{r}^{2}=0,610\right)$; rakip odaklılık ve işletme içi koordinasyon boyutu ile yine pozitif yönlü anlamlı bir ilişki $\left(\mathrm{r}^{2}=0,879\right)$ bulunmaktadır. Korelasyon analizi sonuçlarına göre, $\mathrm{H}_{1 \mathrm{a}}, \mathrm{H}_{1 \mathrm{~b}}$ ve $\mathrm{H}_{1 \mathrm{c}}$ hipotezleri (pazar yönlülük bileşenleri ile mikro işletmelerin yenilik performansı arasında pozitif bir ilişki vardır) kabul edilmektedir. Korelasyon analizi sonuçlarına bağlı olarak, mikro işletmelerin genel anlamda pazar yönlülük, daha ayrıntılı ifade etmek gerekirse müşteri yönlülük ile 
rakip yönlülük ve işletme içi koordinasyon düzeyleri arttıkça yenilik performanslarında da bir yükselme gözlenebileceği tespit edilmiştir.

Bunun yanı sıra, mikro işletmelerin yaşadığı genel işletmecilik sorunları ile yenilik performansları arasında beklendiği üzere ters yönlü ancak istatistiksel olarak anlamlı bir ilişki vardır $\left(\mathrm{r}^{2}=-0,508\right)$; dolayısıyla, $\mathrm{H}_{2}$ hipotezi de aynı şekilde kabul edilmektedir. Mikro işletmelerin yaşadığı genel işletmecilik sorunlarının yenilik performanslarını olumsuz yönde etkileyebileceği, diğer bir deyişle, yaşanan sorunlar arttıkça yenilikçilik performansında bir düşüş; sorunlarda bir azalma yaşandıkça, yenilik performansında da bir yükseliş gözlenebileceği görülmektedir.

Diğer iki hipotezin test edilebilmesi için, korelasyon analizini takiben müşteri yönlülük; rakip yönlülük ve işletme içi koordinasyon ve genel işletmecilik sorunlarının mikro işletmelerin yenilik performansına etkisini tespit etmek amacıyla, backward yöntemi kullanılarak çok değişkenli doğrusal regresyon analizi gerçekleştirilmiştir. Regresyon analizi sonuçları, Tablo 4'te sunulmaktadır.

Regresyon analizi sonuçları, bağımlı değişken durumundaki mikro işletmelerin yenilikçilik performansının \%77,6'sının, müşteri yönlülük, rakip yönlülük ve işletme içi koordinasyon ile genel işletmecilik sorunlarındaki değişim tarafından istatistiksel olarak anlamlı şekilde açıklandığını göstermektedir.

\section{Tablo 4. Regresyon Analizi Sonuçları}

\begin{tabular}{lccccccc}
\hline & $\begin{array}{c}\text { Standartlaşt1- } \\
\text { rılmamış } \\
\text { Katsayılar } \\
\text { (B) }\end{array}$ & $\begin{array}{c}\text { Standartlaşt1- } \\
\text { r1lmış } \\
\text { Katsayılar } \\
\text { (B) }\end{array}$ & t & Sig. & $\mathrm{R}^{2}$ & $\begin{array}{c}\text { Düzletil- } \\
\text { miş R }^{2}\end{array}$ & F* \\
\hline Sabit & 0,628 & - & 6,931 & 0,000 & 0,777 & 0,776 & 1879,136 \\
Müşteri & 0,034 & 0,026 & 1,635 & 0,102 & & & \\
$\begin{array}{l}\text { Yönlülük } \\
\text { Rakip Yönlülük } \\
\text { ve Koordinasyon }\end{array}$ & 0,835 & 0,814 & 47,920 & 0,000 & & & \\
$\begin{array}{l}\text { Genel } \\
\text { Işletmecilik }\end{array}$ & $-0,094$ & $-0,092$ & $-6,755$ & 0,000 & & & \\
Sorunları & & & & & & & \\
\hline
\end{tabular}

* (sig: 0,000)

Faktörlerin mikro işletmelerin yenilik performansı üzerindeki görece etkileri değerlendirildiğinde, mikro işletmelerin rakip yönlülük ve işletme içi koordinasyon düzeyinin yenilik performansı üzerinde görece en yüksek etkiye $(\beta=0,814 ; p<0,01)$ sahip olduğu görülmektedir. Mikro işletmelerin yaşadığı genel işletmecilik sorunları ikinci en önemli etkiye $(\beta=-0,092 ; p<0,01)$ sahip faktör olarak belirlenmiştir. Öte yandan, müşteri yönlülük faktörünün mikro işletmelerin yenilik performansı üzerinde beklenildiği şekilde anlamlı bir etkiye $(\beta=0,026 ; p>0,05)$ sahip olmadı $\breve{g} 1$ tespit edilmiştir. Dolayısıyla, $\mathrm{H}_{3 \mathrm{a}}$ hipotezi reddedilmiş ve yenilik performansı üzerinde istatistiksel olarak anlamlı etkisi olmayan müşteri yönlülük faktörü regresyon analizinde çıkarılarak analiz yenilenmiştir. Yenilenmiş regresyon analizi sonuçları, Tablo 5'te sunulmaktadir. 
N. Turan - İ. Er 9/1 (2017) 281-306

Tablo 5. Yenilenmiş Regresyon Analizi Sonuçları

\begin{tabular}{|c|c|c|c|c|c|c|c|}
\hline & $\begin{array}{l}\text { Standartlaşt1- } \\
\text { rılmamış } \\
\text { Katsayılar } \\
\text { (B) }\end{array}$ & $\begin{array}{l}\text { Standartlaşt1- } \\
\text { r1lmış } \\
\text { Katsayılar } \\
\text { (B) }\end{array}$ & $\mathrm{t}$ & Sig. & $\mathrm{R}^{2}$ & $\begin{array}{l}\text { Düzletil- } \\
\text { miş } \mathrm{R}^{2}\end{array}$ & $\mathrm{~F}^{*}$ \\
\hline Sabit & 0,705 & - & 9,099 & 0,000 & 0,776 & 0,776 & 2814,468 \\
\hline $\begin{array}{l}\text { Rakip Yönlülük } \\
\text { ve Koordinasyon }\end{array}$ & 0,852 & 0,831 & 61,319 & 0,000 & & & \\
\hline $\begin{array}{l}\text { Genel } \\
\text { İşletmecilik } \\
\text { Sorunları }\end{array}$ & $-0,096$ & $-0,093$ & $-6,871$ & 0,000 & & & \\
\hline
\end{tabular}

* (sig: 0,000)

Yenilenmiş regresyon modeli sonuçları, mikro işletmelerin yenilikçilik performansının \%77,6'sının, pazar yönlülüğün rakip yönlülük ve işletme içi koordinasyon bileşeni ile genel işletmecilik sorunlarındaki değişim tarafından istatistiksel olarak anlamlı şekilde açıklandığını göstermektedir. Faktörlerin görece etkileri değerlendirildiğinde, yine mikro işletmelerin rakip yönlülük ve işletme içi koordinasyon düzeyinin, yenilik performansı üzerinde görece en yüksek etkiye ( $\beta=$ $0,831 ; p<0,01)$ sahip olduğu görülmektedir. Mikro işletmelerin yaşadığı genel işletmecilik sorunları da, yine yenilik performansı üzerinde istatistiksel olarak anlamlı ancak beklendiği üzere negatif bir etkiye $(\beta=-0,093 ; p<0,01)$ sahip olduğu tespit edilmiştir.

Yenilenen regresyon analizi sonuçlarına bağlı olarak, $\mathrm{H}_{3 \mathrm{~b}}$ ve $\mathrm{H}_{3 \mathrm{c}}$ hipotezleri kabul edilmekte; pazar yönlülüğün en azından rakip yönlülük ve işletme içi koordinasyon boyutunun mikro işletmelerin yenilik performansı üzerinde pozitif bir etkiye sahip olduğu görülmektedir. Bunun yanı sıra, $\mathrm{H}_{4}$ de hipotezi kabul edilmekte ve mikro işletmelerin yaşadığı genel işletmecilik sorunlarının yenilik performansı üzerinde ters yönlü, diğer bir deyişle negatif bir etkisi olduğu görülmektedir.

\section{Sonuç ve Öneriler}

Bu çalışma, Eskişehir'de faaliyet gösteren esnaf ve sanatkârların sosyo-ekonomik yapısı, temel sorunları ve sorunlarına çözüm önerileri bulmaya yönelik araştırma projesinin bir parçası olup, mikro girişimlerin pazar yönlülük yaklaşımlarının ve yaşadıkları genel işletmecilik sorunlarının yenilik performansları üzerinde etkili olup olmadığını incelemektedir. Bu araştırma, Eskişehir ili özelinde mikro girişimlere ilişkin olarak yapılan ilk kapsamlı çalışma olması açısından önem taşımaktadır. Bu araştırmanın bulguları, ana proje kapsamında değerlendirmeye alınmamış olup yalnızca bu çalışmada değerlendirilmiş, 1769 mikro girişimden toplanan verilerle araştırmanın hipotez testleri gerçekleştirilmiştir.

Araştırmanın bulguları, pazar yönlülüğün rakip yönlülük ve işletme içi koordinasyon bileşeninin büyük işletmeler kadar, mikro girişimlerin de yenilik performansının açısından kritik öneme sahip faktörlerden birisi olduğunu göstermektedir. Mikro girişimlerin uzun vadede pazarda varlıklarını sürdürmelerini sağlayacak yenilikleri gerçekleştirebilmeleri açısından, rakiplerin faaliyetlerindeki değişimleri takip etmeleri ve bu değişimlere ve müşteri ihtiyaçlarındaki değişimlere bağlı olarak işletme içinde koordine şekilde eyleme geçmeleri gerekmektedir. Yalnızca büyük ve orta ölçekli işletmeler açısından değil, mikro girişimler açısından da pazarda 
değişen istek ve ihtiyaçları karşılayacak ve rekabete ayak uydurmayı sağlayacak yenilikleri hayata geçirmek için, pazar yönlülük düzeyini arttıracak işletme becerileri geliştirmeleri son derece önemlidir.

Mikro girişimlerde yenilik performansı üzerinde müşteri yönlülüğün değil de, rakip yönlülük ve işletme için koordinasyonun çok daha önemli bir faktör olarak ortaya çıkması, araştırmanın ilgi çekici bulgularından birisidir. Rakip yönlülük ve işletme için koordinasyonun yenilik performansının temel belirleyicisi olması, mikro girişimlerin önemli rakiplerini sürekli takip ettiklerini, bunlar hakkında düzenli olarak bilgi elde etmeye çalıştıklarını ve rakiplerin faaliyetleri sürekli olarak takip ettiklerini göstermektedir. Böylelikle, kendi stratejilerini geliştirirken rakiplerinin faaliyetlerini mutlaka dikkate aldıklarını ve rekabette kendilerini öne taşıyacak eylemelere yoğunlaştıklarını ifade etmek mümkündür. Bunların yanı sıra, araştırmanın bulgularına göre, tüm rekabet odaklı eylemler gerçekleştirilirken de, işletme içindeki tüm çalışanların ve kaynakların eşgüdümlü olarak kullanılmaya çalışıldığı tespit edilmiştir.

Araştırmada pazar yönlülük dışında, yenilik performansı üzerinde etkili olduğu tespit edilen bir başka faktör ise, mikro girişimlerin yaşadığı genel işletmecilik sorunlarıdır. Mikro işletmeler gerek işletme büyüklüklerine, gerekse faaliyet gösterdikleri işkollarına bağlı olarak; işbirliği ve ortaklık kültürünün gelişmemiş olması, bilgi teknolojisi kullanımındaki yetersiz olma, üretimde ve hizmet sunmada teknolojiden yeterince yararlanamama, yeni fikirler üretmede yetersiz olma, müşterilerine özel mal veya hizmet üretimi gerçekleştirememe, iç ve diş ticarette vizyon eksikliği yaşama gibi çeşitli işletmecilik sorunları ile karşı karşıya bulunmaktadır. Araştırmanın bulguları, mikro girişimlerin yaşadığı bu tür sorunların da yenilikçilik performanslarını olumsuz yönde etkilediğini göstermektedir. Bu bulgular, küçük ve mikro işletmelerin başarı faktörleri ve başarıları önündeki engelleri ele alan çalışmalar (Mead ve Liedholm, 1998; Katwalo, 2010; Franco ve Haase, 2010; Chittithaworn vd. 2011; Philip, 2011) ile paralellik göstermektedir. Diğer bir ifade ile işletmecilik açısından yaşanan bu tür sorunlar, mikro girişimlerin genel olarak faaliyetlerini etkilediği gibi, yenilikleri pazara sunma kapasitelerini de olumsuz biçimde etkilemektedir.

\section{Araştırmanın Kısıtları ve Öneriler}

Araştırma, Türkiye'de mikro işletmelerin pazar yönlülük düzeylerine ilişkin az sayıdaki çalışmadan birisi olmasına karşın, çeşitli kısıtları bulunmaktadır. Öncelikle, Narver ve Slater (1990) tarafından büyük işletmeler dikkate alınarak geliştirilmiş olan MKTOR pazar yönlülük ölçeğinin mikro işletmeler düzeyinde kullanılması, ölçeğin doğal olarak beklendiği şekilde faktörler üretmemesine neden olmuştur. Daha önce gerçekleştirilmiş kimi çalışmalar, küçük ve orta ölçekli işletmelerde MKTOR pazar yönlülük ölçeğinin işlerliğini gösterse de, bu araştırma mikro işletmeler açısından daha verimli bulgular üretecek bir pazar yönlülük ölçeği uyarlaması gerçekleştirilmesi gerekliliğini ortaya çıkarmaktadır. Dolayısıyla, gelecekte mikro ölçekli işletmeler düzeyinde yapılacak çalışmalarda, yeni bir pazar yönlülük yaklaşımı üzerinde çalışılabilir.

Bunun yanında, araştırmanın örneklemi her ne kadar büyük olsa da, araştırma yalnızca Eskişehir ilindeki mikro işletmelerden toplanan verilere dayandığı için, sonuçlar tam anlamıyla Türkiye geneline uyarlanabilir nitelikte olmayabilir. Buna bağlı olarak, gelecekte mikro işletmelerin hem yaşadığı işletmecilik sorunlarının tespiti, hem 
de pazar yönlülük düzeyleri hakkında daha genel bulgulara ulaşabilmek açısından, araştırmanın benzerlerinin Türkiye'deki diğer şehirler, bölgeler, hatta Türkiye genelindeki mikro işletmeleri kapsayacak şekilde yapılmasının faydalı olacağına inanılmaktadir.

\section{Yararlanılan Kaynaklar}

Abramson, N. R., Ai, J. X., (1997). "Using Guanxi-Style Buyer-Seller Relationship in China: Reducing Uncertainty and Improving Performance Outcomes", Thunderbird International Business Review, Vol. 39, No. 6, 765-804.

Acs, Z. J., Desai, S., Hessels, J., (2008). "Entrepreneurship, Economic Development and Institutions", Small Business Economics, Vol. 31, No. 3, 219-34.

Akova, B., Ulusoy, G., Payzın, E., Kaylan, A. R., (1998). "New Product Development Capabilities of the Turkish Electronics Industry", Proceedings of the Fifth International Product Development Management Conference, Como, Italy, 863876.

Altunışık, R., Coşkun, R., Bayraktaroğlu, S., Yıldırım, E., (2012). Sosyal Bilimlerde Araştırma Yöntemleri, 7. Baskı, Seçkin Yayınevi, Ankara.

Alhakimi, W., Baharun, R., (2009). "A Synthesis Model of Market Orientation Constructs Toward Building Customer Value: A Theoretical Perspective", African Journal of Marketing Management, Vol. 1, No. 2, 43- 49.

Alpkan, L., Yilmaz, C., Kaya, N., (2007). "Market Orientation and Planning Flexibility in SMEs", International Small Business Journal, Vol. 25, No. 2, 152-172.

Beck, T., Demirgüc, Kunt, A., Levine, R., (2005). "SMEs, Growth, and Poverty: CrossCountry Evidence”, Journal of Economic Growth, Vol. 10, No. 3, 199-229.

Blankson, C., Stokes, D., (2002). "Marketing Practices in the UK Small Business Sector. Marketing Intelligence \& Planning, Vol. 20, No. 1, 49-61.

Blenker, P., (2000). "The Retarded Kid Brother: In Research of an Adequate Marketing Approach for Small Entrepreneurial Firms", Working Paper No: 2000- 11, University of Aarhus, Denmark.

Brooksbank, R.., Kirby, D., Taylor, D., (2004). "Marketing in Survivor Medium-Sized British Manufacturing Firms: 1987-1997”, Europen Business Review, Vol. 16, No. 3, 292-306.

Bulut, Ç., Yılmaz, C., Lütfihak, A., (2009). "Pazar Oryantasyonu Boyutlarının Firma Performansına Etkileri”, Ege Akademik Bakış, Cilt 9, Sayı: 2, 513 - 538.

Cadogan, J. W., Diamantopoulos, A., (1995). "Narver and Slater, Kohli and Jaworski and the Market Orientation Construct: Integration and Internationalization", Journal of Strategic Marketing, Vol. 3, No. 1, 41-60.

Calantone, J. R., Çavuşlugil, S. T., Zhao, Y., (2002). "Learning Orientation, Firm Innovation Capability, and Firm Performance", Industrial Marketing Management, Vol. 31, No. 6, 515-524.

Caldwell, D. F., O'Reillly, C., (2003). "The Determinants of Team-Based Innovation in Organizations", Small Group Resarch, Vol. 34, No. 4, 497-517. 
Carr, J. C., Lopez, T. B., (2007). "Examining Market Orientation as Both Culture and Conduct: Modeling the Relationship Between Market Orientation and Employee Responses", Journal of Marketing Theory and Practice, Vol. 15, No. 2, 113-123.

Cengiz, E., Ayyıldız, H., Kırkbir, F., (2005). "Yeni Ürün Geliştirme Sürecinin Başarısında Etkili Olan Faktörler", Erciyes Üniversitesi İktisadi ve İdari Bilimler Fakültesi Dergisi, Cilt 24, Sayı: Ocak, Haziran, 133 - 147.

Chittithaworn, C., Islam, A., Yusuf, D.H.M., Keawchana, T., (2011). "Factors affecting business success of small \& medium enterprises (SMEs) in Thailand", Asian Social Science, Vol. 7, No. 5, 180-190.

Cooper, R. G., Kleinschmidt, E. J., (1987). "New Products: What Separates Winners From Losers?", Journal of Production and Innovation Management, Vol. 4, No. 3, 169-84.

Cooper, R.G., (2000). "New Product Performance: What Distinguishes The Star Products", Austria Journal of Management, Vol. 25, No. 1, 17-45.

Damanpour, F., Walker, M. R., Avellaneda, N. C., (2009).“Combinative Effects of Innovation Types and Organizational Performance: A Longitudinal Study of Service Organizations", Journal of Management Studies, Vol. 46, No. 4, 650-675.

Deng, S., Dart, J., (1994). "Measuring Market Orientation: a Multi-Factor, Multi-Item Approach", Journal of Marketing Management, Vol. 10, No. 8, 725-742.

Deshpande, R., Farley, J. U., Webster, F., (1993). "Corporate Culture, Customer Orientation, \& Innovativeness in Japanese Firms: A Quadrad Analysis", Journal of Marketing, Vol. 57, No. 1, 23-37.

Drucker, P., (1973). Management: Tasks, Responsibilities, Practices, Harper \& Row Publishers, New York.

Drucker, P., (1985). "The Discipline Of The Innovator", Harvard Business Review, Vol. 63, No. 3, 67-72.

Edmiston, K., (2007). "The Role of Small and Large Businesses in Economic Development", Economic Review, Second Quarter 2007 (http://www.KansasCityFed.org Erişim Tarihi: 25.05.2016)

Erdil, S., Erdil, O., Keskin, H., (2013). "The Relationships Between Market Orientation, Firm Innovativeness and Innovation Performance", Journal of Global Business and Technology, Vol. 1, No. 1, 4-15.

Everett, M. R., (1983). Diffusion of Innovations, Mc Millan Pub., New York.

Felton, A. P., (1959). "Making the Marketing Concept Work", Harvard Business Review, Vol. 37, No. July/August, 55-65.

Franco, M., Haase, H., (2010). "Failure Factors in Small and Medium-Sized Enterprises: Qualitative Study from an Attributional Perspective", International Entrepreneurship and Management Journal, Vol. 2010, No. 6, 503-521.

Fumo, N. D. G., Jabbour, C. J. C., (2011). "Barriers Faced by MSEs: Evidence From Mozambique", Industrial Management \& Data Systems, Vol. 111, No. 6, 849868. 
Gray, B.J., Matear, S., Boshoff, C., Matheson, P., (1998). "Developing a Better Measure of Market Orientation", European Journal of Marketing, Vol. 32, No. 9, 884-903.

Greenley, G. E., (1995). "Market Orientation and Company Performance: An Empirical Evidence From UK Companies", British Journal of Management, Vol. 6, No. 1, 13.

Günday, G., (2007). "Innovation Models and Implementations at Firm Level in Manufacturing Industry", (Unpublished Master Thesis), Sabanc1 University, İstanbul.

Hagedoorn, J., Cloodt, M., (2003). "Measuring Innovative Performance: Is There An Advantage In Using Multiple Indicators?” Research Policy, Vol. 32, No. 8, 13651379.

Harris, L.C., (1998). "Cultural Domination: to Key to Market-Oriented Culture", European Journal of Marketing, Vol. 32, No. 3/4, 354-373.

Harris, L.C., (2000). "The Organizational Bariers to Developing Market Orientation", European Journal of Marketing, Vol. 34, No. 5/6, 598-624.

Harrison-Walker, L. J., (2001). "Measurement of Market Orientation and its Impact on Business Performance”, Journal of Quality Management, Vol. 6, No. 2, 139-172.

Hill, S. M., Blois, K., (1987). "New Small Technically-Based Firms and Industrial Distributors", International Small Business Journal, Vol. 5, No. 3, 61-65.

Hirschman, E. C., (1983). "Religious Affiliation and Consumption Processes: An Initial Paradigm", Research in Marketing, Vol. 6, 123-131.

Hogarth-Scott S, Watson K., Wilson N., (1996). "Do Small Businesses Have to Practise Marketing to Survive and Grow?", Marketing Intelligence \& Planning, Vol. 14, No. 1, 6-18.

Huang, X., Brown, A., (1999). "An Analysis and Classsification of Problems in Small Business”, International Small Business Journal, Vol. 18, No. 1, 73-75.

Jaworski, B. J., Kohli, A. K., (1993). "Market Orientation: Antecedents and Consequences". Journal of Marketing, Vol. 57, No. 3, 53-70.

Jimenez, D. J., Valle, R. S., (2011). "Innovation, Organizational Learning and Performance", Journal of Business Research, Vol. 64, No. 4, 408-417.

Jimenez-Zargo, A. I., Martinez-Ruiz, M. P., Izquierdo-Yusta, A., (2011). "Key Service İnnovation Drivers in The Tourism Sector: Empirical Evidence and Managerial Implications", Service Business, Vol. 5, No. December, 339 - 360.

Jones, R., Rowley, J., (2011). "Entrepreneurial Marketing in Small Business: A Conceptual Exploration", International Small Business Journal, Vol. 29, No. 1, 25-36.

Karadeniz, E., Göçer, K., (2007), "Internationalization of Small Firms: A Case Study of Turkish Small-and Medium-Sized Enterprises", European Business Review, Vol. 19, No. 5, 387-403. 
Karahan, K., Özçiftçi, V., (2008). "Pazar Yönlülük: Aksaray İli Perakende Hizmet İşletmelerinde Bir Uygulama", Selçuk Üniversitesi Sosyal Bilimler Enstitüsü Dergisi, Sayı: 20, $479-492$.

Katwalo, A. M., (2010). "Competence and Critical Success Factor Development as an Avenue for Achieving Sustainable Micro and Small Enterprises in Africa", Journal of Management Policy \& Practice, Vol. 11, No. 5, 139-144.

Kivimöki, M., Lansisalmi, H., Elovainio, M., Heikkila, A., Lindstrom, K., Harisalo, R., Sipila, K. ve Puolimatka, L., (2000). "Communication as a Determinant of Organizational Innovation”, R\&D Management, Vol. 30, 33-42.

Kohli, A. K., Jaworski, B. J., (1990). "Market Orientation: The Construct, Research Propositions, and Managerial Implications", Journal of Marketing, Vol. 54, No. 2, $1-18$.

KOSGEB, (2011). KOBİ Stratejisi ve Eylem Planı 2011-2013, (Erişim Adresi: http://www.tobb.org.tr/SiteAssets/Lists/DuyurularListesi/EditForm/KSEP\%20201 1-2013.pdf).

Kotler, P., Levy, S. J., (1969). "Broadening the Concept of Marketing", Journal of Marketing, Vol. 33, No. 1, 10-15.

Kotler, P., (2003). Marketing Insights from A to Z: 80 Concepts Every Manager Needs To Know, New Jersey, Wiley.

Lear, R. W., (1963). "No Easy Road to Market Orientation”, Harvard Business Review, Vol. 41, No. 5, 73-80.

Lee, J., Miller D., (1999). "People Matter: Commitment to Employees, Strategy and Performance in Korean Firms", Strategic Management Journal, Vol. 20, No. 6, 579-593.

McCartan-Quinn, D., Carson, D., (2003). 'Issues Which İmpact Upon Marketing in the Small Firm', Small Business Economics, Vol. 21, No. 2, 201-213.

McNamara, C. P., (1972). "The Present Status of the Marketing Concept", Journal of Marketing, Vol. 36, No. 1, 50-7.

Mead, D., Liedholm, C., (1998). "The Dynamics of Micro and Small Enterprises in Developing Countries", World Development, Vol. 26, 61-74.

Meeus, M. T. H., Oerlemans, L. A. G., (2000). "Firm Behaviour and Innovative Performance: An Empirical Exploration of the Selection-Adaptation Debate", Research Policy, Vol. 29, No. 1, 41-58.

Messikomer, E. E., (1987), "Marketing Changes the Corporate Culture - A Company Study", The Journal of Business \& Industrial Marketing, Vol. 2, No. 4, 53-8.

Narver, J. C., Slater, S. F., (1990). "The Effect of a Market Orientation on Business Profitability", Journal of Marketing, Vol. 54, No. 4, 20 - 35.

Neely, A., Hii, J., (1998). "Innovation and Business Performance: A Literature Review", The Judge Institute of Management Studies, University of Cambridge: London. 
Nikoomaram, H., Maatoofi, A. R., (2011). "The Effect of Learning Orientation on Market Orientation and Performance in Small-Sized Firms: Evidence From Iran", European Journal of Social Sciences, Vol. 18, No. 4, 632 - 642.

Oke, A., (2007), "Innovation Types and Innovation Management Practices in Service Companies", International Journal of Operations and Production Management, Vol. 27, No. 6, 564-587.

OECD (2005). Oslo Manual: Proposed Guidelines for Collecting and Interpreting Technological Innovation Data, 2nd Ed., (Erişim Adresi: https://www.oecd.org/innovation/inno/oslomanualproposedguidelinesforcollecting andinterpretingtechnologicalinnovationdata2ndedition.htm)

Peçen, Ü., Kaya, N., (2013). “Amerika Birleşik Devletleri Firmalarında İnsan Kaynakları Yönetimi Uygulamaları, Organizasyonel İklim ve Organizasyonel Yenilikçilik Düzeyi”, Doğuş Üniversitesi Dergisi, Cilt 14, Sayı: 1, 95-111.

Pelham, A. M., Wilson, D., (1996). "A Longitudinal Study of the Impact of Market Structure, Firm Structure, Strategy and Market Orientation Culture on Dimensions of Small-Firm Performance", Journal of The Academy of Marketing Science, Vol. 24, No. 1, 27-43.

Peters, T. J., Waterman, R. H., (1982). In Search of Excellence: Lesson from America's Best-Run Companies, Harper Row, New York.

Philip, M., (2011), "Factors Affecting Business Success of Small \& Medium Enterprises (SMEs)", Amity Global Business Review, Vol. 6, Issue 1, 118-136.

Pitt, L. Carauna, A., Berthon, P. R., (1996). "Market Orientation and Business Performance: Some European Evidence", International Marketing Review, Vol. 13, No. 1, 5-18.

Robicheaux, R. A., Coleman, J., (1994). "The Structure of Marketing Relationships", Journal of the Academy of Marketing Science, Vol. 22, No: Winter, 38-51.

Ruekert, R. W., (1992). "Developing a Market Orientation: An Organisational Strategy Perspective", International Journal of Research in Marketing, Vol. 9, No. 3, 225245.

Rogers, E., (2003). Diffusion of Innovations, Free Press, New York.

Schumpeter, J., (1912). The Theory of Economic Development: An Inquiry into Profits, Capital, Credit, Interest and the Business Cycle, Harvard University Press, Cambridge: MA.

Selnes, F., Jaworski, B. J., Kohli, A. K., (1996). "Market Orientation in United States and Scandinavian Companies: A cross-Cultural Study", Scandinavian Journal of Management, 1Vol. 2, No. 2, 139-157.

Sheikh, S., Pecher, I, Steiber, N., Heckl, E., (2002). "Support Services for Micro, Small, and Sole Proprietor's Businesses", European Commission's Enterprise Directorate, Brussels.

Slater, S. F., Narver, J. C., (1994). "Does Competitive Environment Moderate the Market Orientation-Performance Relationship?", Journal of Marketing, Vol. 58, No. $1,46-55$. 
Smith, M. H., Smith, D., (2007), "Implementing Strategically Aligned Performance Measurement in Small Firms", International Journal of Production Economics, No. 106, Vol. 2, 393-408.

Spillan, J. E., Li, X., Totten, J. W., Mayolo, C. A., (2009). “An Exploratory Analysis of Market Orientation of Small and Medium -Sized Business (SMEs) in Peru", Panorama Socioeconomico, Vol. 27, No. 39, 136 - 149.

Stel, A. V., Carree, M., Thurik, R., (2005). "The Effect of Entrepreneurial Activity on National Economic Growth", Small Business Economics, Vol. 24, No. 3, 311-21.

Sevim, N., (2013). Küçük İşletme Yönetimi, Anadolu Üniversitesi AÖF Yayıı No: 2819/1777, Saray Matbaacilık, Ankara.

Tung, J., (2012). "A Study of Product Innovation on Firm Performance", The International Journal of Organizational Innovation, Vol. 4, No. 3, 84 - 97.

TÜİK, (2009). TÜİK İstatistikleri, (http:www.tuik.gov.tr Erişim Tarihi: 25.05.2014).

van Praag, M., Versloot, P., (2007). "What is The Value of Entrepreneurship? A Review of Recent Research", Small Business Economics, Vol. 29, No. 4, 351-82.

Wang, Y., Costello, P., (2009). "An Investigation into Innovations in SMEs: Evidence from the West Midlands, UK”, Journal of Entrepreneurship, Vol. 18, No. 1, 65-93.

Webster, F. E., (1994). Market Driven Management, Wiley, London.

Yau, O. H. M., McFetridge, P. R., Chow, R. P. M., Lee, J. S. Y., (2000). "Is Relationship Marketing for Everyone?", European Journal of Marketing, Vol. 34, No. 9/10, 1111-1127.

Yörük, N., Ban, Ü., (2003). Kobi'lerin Finansman Sorunları ve Finansman Sorunlarının Kaynaklarının Belirlenmesine Yönelik Uygulama, Gazi Kitapevi, Ankara.

Zengin, H., Ekber, Ş., (2012). "Pazar Odaklılık Ölçeklerinin Tüketici Algılamaları Esasında Değerlendirilmesi”, Sakarya İktisat Dergisi, Cilt 1, Say1: 2, 26-45.

Zortea-Johnston, e., Darroch, J., Matear, S., (2012). "Business Orientations and Innovation in Small and Medium Sized Enterprises", International Entrepreneurship and Management Journal, Vol. 8, No. 2, 145-164.

http://www.tuik.gov.tr/PreHaberBultenleri.do?id=13146 Erişim tarihi: 22.06.2015.

http://www.tuik.gov.tr Erișim tarihi: 22.06.2015.

http://www.tsv2023.org Erișim tarihi: 28.04.2015.

http://www.tuik.gov.tr/PreHaberBultenleri.do?id=21864 Erişim Tarihi: 21.03.2017 


\section{Effect of Market Orientation on Innovation Performance of Micro Enterprises: Research on Micro Enterprises in Eskişehir}

\author{
Nurcan Turan \\ Anadolu University \\ Faculty of Economics and Administrative \\ Sciences, Department of Business \\ Administration, Eskişehir, Turkey \\ nturan@anadolu.edu.tr
}

\author{
İçlem Er \\ Dumlupinar University \\ Faculty of Economics and Administrative \\ Sciences, Department of International \\ Trade and Finance, Kütahya, Turkey \\ iclem.er@dpu.edu.tr
}

\section{Extensive Summary}

Micro enterprises are one of the major contributors of national economies of developed and developing countries (Fumo and Jabbour 2011; Stel et al., 2005; van Praag and Versloot, 2007; Karadeniz and Göçer, 2007; Acs et al., 2008; Beck et al., 2005). Most economic studies define micro enterprises as business with less than 10 employees, and usually they are considered to be an important source of employment and provide self employment opportunity (Sheikh et al., 2002; Edmiston, 2007). They are not only seen as a main driver for generating employment, they also promote innovation, realize business ideas, increase regional economic integration, and maintain social stability (Franco and Haas, 2010). Since micro enterprises play a significant role in Turkish economy, it is therefore critical to develop and understanding why these businesses succeed or fail.

Drucker (1973) argues that creating and keeping customers is the only valid purpose of a business, for achieving this purpose businesses should focus on only two functions: Marketing and innovation. The essential success factor for micro enterprises is selling products and services at profitable terms. However, this can only be achieved in the competitive business environment by developing relationship with customers and retaining them by providing value to customers through new products and services. These relationships will provide viability in the long run and sustain cash flow. Yet, the central question here is how micro enterprises would establish and retain relationships that will add value to the customers and earn profits.

Marketing philosophies, such as market orientation would help micro enterprises, like their larger counterparts, to develop and retain customer relationships that would allow them to keep up with their competitors. Since Narver and Slater (1990) revealed a positive relationship between firm performance and market orientation in large firms, it is suggested that the market orientation construct is applicable in research on small businesses.

Furthermore, business environment dictates for small and medium-sized enterprises (SMEs) that success starts with investigating the customers' needs, and developing differentiated products or services for a well-defined segment (ZorteaJohnston et al., 2012). Thus, requiring small and medium-sized, and likewise micro enterprises to focus on customers and develop market driven innovations, since they are strategically and tightly aligned with the market in such a way that they put their 
customers' expressed needs first before creating appropriate products to meet these explicit needs (Deshpande et al., 1993). Following this research path, recent studies investigated the link between market orientation and innovation performance of firms, and depicted a positive relationship that market orientation enhances innovation performance (Bulut et al., 2009; Jimenez-Zargo et al., 20121; Tung, 2012; ZorteaJohnston et al., 2012; Erdil vd. 2013).

On the other hand, research indicates that failure of SMEs is high, above all within the first years after starting, and shows that over $20 \%$ of new ventures fail within one year and 66\% within six years (Franco and Haas, 2010). SMEs and particularly micro enterprises encounter several business challenges and problems, such as liquidity constraints, lacking innovative capacity, lack of developing firm-specific assets, lack of deployment of technology, lack of coopration and collaboration, etc., which lead to business failures (Franco and Haas, 2010). These business challenges not only affect firm performance but also innovation performance of SMEs and micro enterprises.

Accordingly, this research aims to identify the impact of market orientation and business challenges of micro enterprises on their innovation performance operating in Eskişehir. This study is part of a research project that aims to identify the structures and main problems of micro enterprises that operate in Eskişehir, and provide suggestions for improvement, and contributes to the literature by being the first comprehensive study on micro enterprises in Eskişehir. The variables and research model is presented in Figure 1.

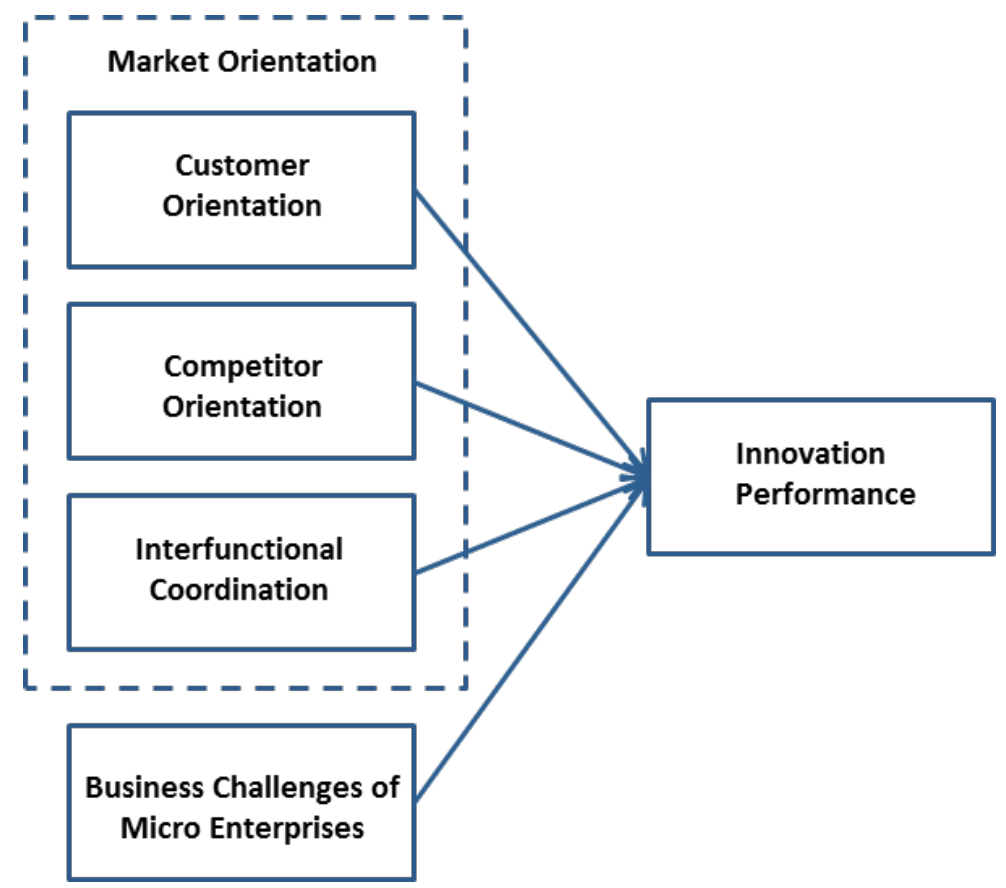

Figure 1. Research Model

The hypothesis for this study addresses the relationship between three components of market orientation, business challenges and innovation performance of micro enterprises:

$\mathbf{H}_{1 \mathbf{a}}$ : There is a positive relationship between customer orientation component of market orientation and innovation performance of micro enterprises. 
$\mathbf{H}_{1 \mathbf{b}}$ : There is a positive relationship between competitor orientation component of market orientation and innovation performance of micro enterprises

$\mathbf{H}_{1 \mathbf{c}}$ : There is a positive relationship between inter-functional coordination component of market orientation and innovation performance of micro enterprises.

$\mathbf{H}_{2}$ : There is a negative relationship between business challenges and innovation performance of micro enterprises.

$\mathbf{H}_{3 \mathbf{a}}$ : Customer orientation component of market orientation has a positive impact on innovation performance of micro enterprises.

$\mathbf{H}_{3 \mathbf{b}}$ : Competitor orientation component of market orientation has a positive impact on innovation performance of micro enterprises.

$\mathbf{H}_{3 \mathbf{c}}$ : Inter-functional coordination component of market orientation has a positive impact on innovation performance of micro enterprises.

$\mathbf{H}_{4}$ : Business challenges have a negative impact on innovation performance of micro enterprises.

\section{Sample and Data Collection}

Research data was collected via face-to-face interviews with owners/managers of micro enterprises in Eskişehir. The survey questionnaire was prepared according to interviews with executives of Eskişehir Chamber of Tradesmen and Craftsmen, and finalized after a pilot survey with 120 micro enterprises. Due to participation rates research comprises data collected from 1769 micro enterprises.

\section{Findings}

For testing the research hypothesis, we needed to conduct correlation and regression analysis. However, before those analyses, we conducted an exploratory factor analysis to determine whether the sub-dimensions of the market orientation scale were observed in the data set. The exploratory factor analysis produced two subdimensions for market orientation (MKTOR) scale instead of three, customer orientation and, competitor orientation-intraenterprise coordination, which was an expected outcome of micro enterprises as the MKTOR scale was developed and mostly tested with data from large businesses. Following the exploratory factor analysis, we performed reliability analysis for the emerging sub-dimensions of MKTOR scale, business challenges and innovation performance scales, and detect that the calculated Cronbach's alpha values vary between 0,807 and 0,957 , which could be considered highly reliable.

We conducted correlation analysis for testing $\mathrm{H}_{1 \mathrm{a}}, \mathrm{H}_{1 \mathrm{~b}}, \mathrm{H}_{1 \mathrm{c}}$ and $\mathrm{H}_{2}$. According to the results of the analysis, there are positive correlations between customer orientation $\left(r^{2}=0,610\right)$, competitor orientation-intraenterprise coordination $\left(r^{2}=0,879\right)$ and innovation performance. In addition, correlation analysis results showed that there is a negative correlation between business challenges that micro enterprises encounter $\left(r^{2}=-\right.$ $0,508)$ and their innovation performances, as anticipated. Thus, the results support $\mathrm{H}_{1}$ and $\mathrm{H}_{2}$.

We performed a regression analysis with backward method for testing $\mathrm{H}_{3 \mathrm{a}}, \mathrm{H}_{3 \mathrm{~b}}$, $\mathrm{H}_{3 \mathrm{c}}$ and $\mathrm{H}_{4}$, to estimate the variance explained in innovation performance by market orientation sub-dimensions and business challenges encountered. The results of the 
regression analysis indicate that $77,6 \%$ of the variation in micro enterprises' innovation performance is explained by the dependent varibales (Adjusted $\mathrm{R}^{2}=0,776 ; \mathrm{F}=1879,136$; $p<0,01)$. In regression analysis beta values of each independent variable signifies the contribution and impact on innovation performance. The results suggested that customer orientation with beta value of 0,034 and t-value of 1,635 $(p=0,102)$ might have have an impact on innovation performance of micro enterprises but not significantly. Thus, $\mathrm{H}_{3 \mathrm{a}}$ is rejected and, we excluded customer orientation variable and repeated the backward method regression analysis.

The results of the renewed regression analysis suggest that competitor orientationintraenterprise coordination, and business challenges that micro enterprises encounter could explain $77,6 \%$ of the variation in innovation performance (Adjusted $\mathrm{R}^{2}=0,776$; $\mathrm{F}=2814,468 ; p<0,01)$. When beta values of indepent variables evaluated, competitor orientation-intraenterprise coordination sub-dimension has the highest beta value of 0,831 , thus which has the highest impact on innovation performance of micro enterprises. The variable business challenges that micro enterprises encounter has also an impact on innovation performance those firms, however, comparatively a minor one with a beta value of $-0,093$. Accordingly, $\mathrm{H}_{3 b}$ and $\mathrm{H}_{3 c}$ are accepted indicating that competitor orientation-intraenterprise coordination has a strong positive impact on innovation performance of micro enterprises. $\mathrm{H}_{4}$ is also accepted suggesting business challenges that micro enterprises encounter impacts innovation performance in a negative fashion as anticipated.

\section{Discussion}

The findings indicate that market orientation is a significant determinant of innovation performance of micro enterprises. As the level of market orientation, in other words customer and competitor orientation, and intraenterprise coordination levels increase, there would be an upward inclination in the innovation performances of micro enterprises. In addition, the findings also imply that as the business challenges that micro enterprises encounter intensify, their innovation performance would exhibit a downward inclination.

For micro enterprises business vialibity in long run requires enhancing innovation performance that would revive business profitibality through developing new products and services. Market orientation is one of the key factors that would facilitate the process, and thus it is essential to increase market orientation by tracking the changes in competitors' activities and to react accordingly with an intraenterprise coordination of resources while considering the changes in customers' needs and wants.

Furthermore, business challenges such as lack of collaboration and cooperation culture, lack of utilization of information technologies, lack of employing new technologies for developing new products and services, lack of innovative ideas, and lack of providing customized products and services for customers impede on innovation performance of micro enterprises. Any improvement in these areas that would diminish overall business challenges would significantly affect innovation performance in positive fashion. 